\title{
Los programas de crédito educativo y subsidio a la demanda: instrumentos para el mejoramiento o deterioro de la igualdad en la educación superior en Colombia*
}

\author{
Education Credit and Demand Subsidy Programmes: Instruments to either Improve or Worsen the Equality in \\ Higher Education in Colombia
}

\author{
Aura Maria Moreno Gamba ${ }^{a}$ \\ Universidad Católica de Colombia, Colombia \\ aura-moreno@javeriana.edu.co \\ ORCID: https://orcid.org/0000-0001-8096-1239
}

DOI: https://doi.org/10.11144/Javeriana.papo25.pces

Recibido: 30 Noviembre 2018

Aceptado: 27 Septiembre 2019

Publicado: 23 Diciembre 2020

\section{Resumen:}

Desde la década de los años 80, múltiples países latinoamericanos, entre ellos Colombia, identificaron como fuente potencial para la reducción de cargas fiscales, el uso de programas focalizados que atenúen el gasto público y centralicen su accionar en aquellas personas que lo requieran, por lo cual, las diferentes instituciones gubernamentales han optado por iniciativas que promuevan el acceso a la educación superior de la población a través de diferentes instrumentos como son los programas de crédito educativo y subsidio a la demanda, enmarcados en un enfoque de igualdad de oportunidades, donde el mérito y la condición de pobreza se convierten en los garantes del acceso a la educación superior.

Sin embargo, dichos instrumentos han sido estructurados bajo un conjunto de condiciones relacionadas tanto con el nivel socioeconómico, como con el logro educativo de la población, excluyendo al conjunto de individuos que no cumplen con las condiciones previamente establecidas y consolidando un escenario de acceso restringido y sin cupo para los estudiantes en Colombia.

A partir del análisis de las bases de datos provenientes de diferentes fuentes gubernamentales y de entrevistas semiestructuradas desarrolladas a beneficiarios de los programas Ser Pilo Paga, Tú Eliges y Crédito Acces, se permite entrever las diferentes implicaciones que dichos programas focalizados traen consigo para la igualdad en la educación superior en el país.

Palabras clave: programas, educación superior, acceso, focalización.

\section{Abstract:}

Since the 1980s many Latin-American countries — including Colombia — identified as a potential source to reduce the tax burden, the use of focused programmes intended to mitigate the public expenditure and centralize their actions in order to serve the people in need. Therefore, the different governmental institutions have chosen to follow initiatives that foster the access to higher education based on different instruments just like the education credit and demand subsidy programmes under an approach of equal opportunities. In these programmes, merit and poverty become the factors considered to grant access to higher education. However, these instruments have been structured according to some conditions related both to the socioeconomic level and the educative achievements in this population. These programmes exclude those individuals who are not in the abovementioned conditions and this way they define a scenario where access and placements are restricted for many students in Colombia.

The analysis of databases from different governmental sources and some semi-structured interviews to beneficiaries from the programmes "Ser Pilo Paga", "Tú Eliges" and "Crédito Acces" provides insight into different consequences from these focused programmes regarding the equality in higher education in Colombia.

Keywords: programmes, higher education, access, focusing.

\section{Introducción}

El acceso a la educación superior en Colombia se ha convertido en tema de debate y preocupación por parte de los tomadores de decisiones a nivel nacional, ya que gran cantidad de la población colombiana cuenta con pocas posibilidades de acceder a este nivel educativo, ya sea por sus resultados en pruebas de Estado, por las

Notas de autor

$$
\text { a Autora de correspondencia. Correo electrónico: aura-moreno@javeriana.edu.co }
$$


condiciones previas que determinan su éxito en la obtención de cupos en instituciones universitarias públicas o por las condiciones socioeconómicas que impiden costear o financiar la matrícula en una universidad privada $^{1}$.

Se ha determinado que la desigualdad en el acceso a la educación superior está directamente asociada con las condiciones económicas, sociales y culturales de la población, y que el sistema educativo ha volcado su acción en la reproducción de dichas desigualdades al privilegiar a los individuos mejor situados de la sociedad. Existe una exclusión de la población de estratos bajos de la educación superior, ya que sus ingresos no les permiten el acceso a una educación privada, y la baja calidad de la educación básica y media que reciben no les permite alcanzar elevados puntajes que les garantice el acceso a los pocos cupos ofertados en la educación superior pública (Sánchez y Otero, 2012). El acceso a la educación superior se ve determinado por las condiciones económicas de los hogares, el nivel de escolaridad de los padres, el tamaño del hogar y el valor de la matrícula, lo que conduce, a su vez, al favorecimiento de las clases altas.

El rendimiento en las pruebas de suficiencia está igualmente influenciado por la calidad de la educación impartida en las instituciones públicas. Los estudiantes que presentan mayor capacidad de pago y acceden a instituciones privadas de matrículas elevadas son los que presentan mejores puntajes en las pruebas; de tal manera se enfatiza que la suerte de las personas para acceder a la educación superior está relacionada con su origen y clase social (García et al., 2013).

Igualmente, el pertenecer a determinado grupo, ya sea LGBTI, afrocolombiano, étnico, etc., condiciona el acceso y participación en las oportunidades de tipo económico y social, gestando diferencias que se consolidan a lo largo de generaciones, a través de discriminación, segregación y estigmatización, condicionando igualmente la movilidad social de esta población (Montenegro y Meléndez, 2014). Las posibilidades de acceso a la educación superior son considerablemente reducidas, específicamente para los grupos étnicos y raciales en Colombia, mientras que la relación de asistencia a una institución de educación superior para la población afrocolombiana corresponde a uno de cada cinco, para el caso de la población indígena tan solo asciende porcentualmente al 7.4\% (Montenegro y Meléndez, 2014, p. 551).

Por su parte, para la población que se encuentra en condición de discapacidad se evidencia que aproximadamente 3 de cada 100 personas con nivel educativo medio o universitario presentan algún tipo de discapacidad permanente, lo cual indica que dicha población cuenta con dificultades para ingresar a niveles de educación superior (Montenegro y Meléndez, 2014). De igual manera, se identifica que "un $60 \%$ de la población en estado de discapacidad se encuentra por fuera del mercado laboral y del estudio, contrastado con un 35\% para el resto de la población” (Montenegro y Meléndez, 2014, p. 571).

De la misma manera, al contar con instituciones diferenciadas y con pocas posibilidades en el acceso a las mismas, se presenta una situación de desigualdad social, ya que el acceso es garantizado solo a aquellas personas que cumplan con lineamientos establecidos, sean de tipo económico o del capital académico adquirido previamente. De tal manera, gran cantidad de estudiantes tienen que acudir a la financiación de su educación por medio de créditos educativos en instituciones de educación privadas, como única opción para poder acceder al sistema de educación superior.

La incapacidad en el acceso a la educación superior que presenta gran cantidad de la población conduce a que se genere una reproducción de desigualdades sociales, culturales y económicas, ya que la población que no logra acceder al sistema ve limitados sus ingresos, sus capacidades y sus proyecciones de vida. Con el objetivo de contribuir a mejorar dicha situación, las diferentes instituciones gubernamentales han buscado iniciativas que promuevan el acceso a la educación superior de la población a través de diferentes instrumentos como son los programas de crédito educativo y subsidio a la demanda, enmarcados en un modelo de igualdad de oportunidades. Sin embargo, dichos instrumentos han sido estructurados bajo un conjunto de condiciones relacionadas tanto con el nivel socioeconómico, como con el logro educativo de la población, excluyendo al conjunto de individuos que no las cumplen, y consolidando un modelo de acceso restringido y sin cupo en la educación superior en Colombia. 
Por esta razón es indispensable conocer si los programas de crédito educativo y subsidio a la demanda han conducido a reproducir o neutralizar los mecanismos que reproducen la desigualdad en la educación superior en Colombia, esto a través del análisis de los diversos conceptos teóricos de la desigualdad y los mecanismos reproductores de la misma; así como de la caracterización de los programas de crédito educativo y subsidio a la demanda, y del análisis cualitativo de información estadística consolidada que permita evidenciar el tipo de población beneficiaria, los condicionamientos a los cuales se encuentran enfrentados dichos beneficiarios y la existencia o no de mecanismos que amplíen las brechas de desigualdad en el sistema de educación superior en Colombia.

De acuerdo con el análisis de las investigaciones elaboradas sobre la temática de interés, resulta claro que existen grandes indicios respecto a la presencia de desigualdades en el sistema de educación superior en Colombia. Asimismo, los estudios permiten evidenciar la existencia de posibles mecanismos reproductores de desigualdades sociales, relacionados con la jerarquía para el acceso a la educación superior, donde prima la población beneficiada por factores económicos, sociales y culturales. Sin embargo, aun cuando amplios estudios permiten vislumbrar un panorama general de las condiciones de desigualdad en la educación superior, existe una deficiencia relacionada con la falta de claridad frente al debate sobre la igualdad de oportunidades y de posiciones, así como la identificación de los mecanismos que reproducen dicha desigualdad; por consiguiente, es importante evidenciar si, efectivamente, con la implementación de los créditos educativos aquí abordados se propende por la igualdad de oportunidades o de posiciones, y si dichos programas han conducido, a su vez, a reproducir o neutralizar los mecanismos generadores de desigualdad que conduzcan a la eliminación o ampliación de las brechas sociales.

\section{Hacia un concepto de desigualdad y los mecanismos que la reproducen}

Inicialmente los problemas de la desigualdad han sido analizados desde el punto de vista de las teorías de la justicia, que la conciben como un problema asociado a la explotación, el aprovechamiento y la obtención de recursos económicos. Desde el punto de vista sociológico, se encuentran los planteamientos desarrollados por Tilly y Therborn. Desde la perspectiva de Tilly, la desigualdad humana es concebida como aquella distribución dispareja, entre un conjunto de individuos, categorías o regiones, respecto de atributos o condiciones (Tilly, 2000). Por su parte, para Therborn la desigualdad es analizada desde el marco de las capacidades, pues afirma que esta se constituye como una violación de la dignidad de los individuos, ya que les impide desarrollar a plenitud sus capacidades. En este mismo marco, la desigualdad se constituye como un ordenamiento sociocultural, en el cual se deteriora la capacidad de actuación, la salud, el sentido de identidad y los recursos para lograr una vida participativa (Therborn, 2015).

Para Therborn (2015) existen tres tipos de desigualdad asociados con las condiciones de vida humana, con el desarrollo personal de los individuos y con los recursos económicos. Específicamente, en la sociedad se produce la "desigualdad vital" la cual está asociada con las posibilidades de vida que se tienen disponibles; asimismo se encuentra la "desigualdad existencial", relacionada con la asignación de atributos que impiden que el individuo desarrolle su personalidad, dignidad o sus derechos; y, finalmente, la "desigualdad de recursos", la cual se concibe como la desigualdad en la adjudicación de recursos económicos para funcionar (Therborn, 2015, p. 54).

Por otra parte, Tilly (2000) analiza aquella desigualdad que se reproduce socialmente, la que se caracteriza por ser persistente o perdurar entre diferentes relaciones sociales, tanto en la vida como en la historia. Para él, las desigualdades que son significativas y representativas socialmente se producen por diferencias categoriales como, por ejemplo, negro/blanco, hombre/mujer, etc., en lugar de desempeños individuales. Para Tilly:

una categoría consiste en un conjunto de actores que comparten un límite que distingue de al menos otro conjunto de actores visiblemente excluidos por ese límite y los relaciona con ellos. Una categoría simultáneamente aglutina actores juzgados 
semejantes, escinde conjuntos de actores considerados desemejantes y define relaciones entre ambos (Zerubavel, 1996). (Tilly, 2000 , p. 75)

La desigualdad persistente surge por causa del control que ejercen algunos actores sobre el acceso a determinados productos generadores de valor, mediante la implementación de distinciones o pares categoriales, con el objetivo de generar soluciones para los problemas organizacionales que puedan surgir.

De tal manera, las desigualdades que surgen por pares categoriales, es decir, desigualdades pareadas, se constituyen en relaciones irregulares que presentan una división reconocida por la sociedad, que se genera constantemente en diferentes situaciones, y conduce a una exclusión desigual de los recursos que son controlados por una de las partes (Tilly, 2000). Las desigualdades categoriales persisten en el tiempo debido al fortalecimiento de diferentes mecanismos que amplían las brechas sociales, mecanismos en los cuales determinados grupos sociales se encuentran en desventaja, sufriendo de privaciones o minimizando su actuación en la sociedad.

Algunos estudios han tratado de no solo definir qué desigualdades son injustas o por qué es injusta la desigualdad, sino que también han enmarcado los diferentes mecanismos por los cuales se reproduce la desigualdad en la sociedad. Tal es el caso de Tilly (2000), quien establece la existencia de un conjunto de mecanismos por los cuales se reproducen constantemente las desigualdades categoriales.

Para Tilly (2000), el mecanismo de explotación actúa como resultado de una situación en la cual un conjunto de individuos controlan un recurso que es considerado valioso, y cuya actividad requiere un esfuerzo, materializado en trabajo, obtenido a través del esfuerzo de otros individuos que son excluidos, a su vez, de la utilidad o valor final de dicho esfuerzo. Este mecanismo de reproducción se encuentra relacionado con la teoría marxista, en la cual la explotación actúa como instrumento de control, se gestan grupos sociales diferenciados y se consolida un conflicto de clases. La explotación representa claramente la dinámica de exclusión e inclusión reflejada tanto en la relación de esclavo y amo, como en la de trabajador y patrono. Dentro de la desigualdad categorial, este mecanismo contribuye a beneficiar a la población que se encuentra mejor situada o que cuenta con poder sobre otro conjunto de la población.

Adicional al mecanismo de explotación, se encuentra el acaparamiento de oportunidades de determinado conjunto de la población que no pertenece a la élite. En comparación con la explotación, el acaparamiento de oportunidades no tiene como objetivo la obtención de beneficios a través del aprovechamiento del esfuerzo de otros, por el contrario, excluye a individuos del acceso a bienes o recursos necesarios (Tilly, 2000). Ante la relación elite-explotación, en este segundo mecanismo analizado actúan la población no elitista y el acaparamiento de oportunidades, en la cual estos individuos se conforman con la obtención de recursos que no son explotados aún por la élite.

Por otra parte, se encuentra el mecanismo de emulación, el cual es activado o reforzado por los dos mecanismos previos. Este mecanismo, de acuerdo con Tilly (2000), se constituye como una adopción de estructuras o modelos de organización que ya son implementados y desarrollados en otros ámbitos:

La emulación funciona a lo largo y lo ancho del mundo social e incluye la adopción de modelos igualitarios de interacción sociales, tanto iguales como desiguales: compuestos de cadenas, tríadas, organizaciones y conjuntos categoriales que pueden o no articularse con jerarquías. (Tilly, 2000, p. 107)

$\mathrm{Al}$ adoptar o implementar diferentes modelos organizaciones de otros lugares, se adquieren condiciones de jerarquías y categorías de desigualdad propias de dichos modelos.

Adicional a los mecanismos mencionados, Tilly (2000) toma en consideración la adaptación que se caracteriza no por favorecer directamente la creación de desigualdades categoriales, sino por contribuir a su mantenimiento:

La adaptación, como la emulación, es un mecanismo social extremadamente general, ampliamente presente fuera del reino de la desigualdad. Tiene dos componentes principales: la invención de procedimientos que facilitan la interacción cotidiana y la elaboración de relaciones sociales valoradas alrededor de las divisiones existentes. (Tilly, 2000, p. 109) 
Dichos mecanismos contribuyen a la generación de desigualdades persistentes, en las cuales los individuos se encuentran en desventaja frente a sus pares, impidiendo el acceso a los mismos bienes y servicios sociales. Igualmente, los pares categoriales están determinados por condiciones e interacciones sociales más que por características individuales (Tilly, 2000).

A partir de los planteamientos establecidos, Therborn determina que las desigualdades son producidas socialmente a través de un conjunto de ordenamientos y de actividades distributivas, las cuales operan bajo determinados mecanismos.

Estos mecanismos corresponden al distanciamiento, a la explotación, la exclusión y la jerarquización. Para Therborn (2015), el distanciamiento hace referencia a la distancia presente entre dos individuos, debido a que uno de ellos puede estar en mejores condiciones dadas las oportunidades obtenidas por ayuda de sus padres, por mejor capacitación o por un mayor esfuerzo; y el otro, por su parte, puede estar rezagado por falta de conocimiento, por inadecuadas condiciones de salud o simplemente por desconfianza en sí mismo. A este mecanismo se le atribuye el logro como fuente de recompensa, y es analizado como

\begin{abstract}
El discurso liberal e individualista suele denominar "logro" a este mecanismo, en el que no ve una producción de desigualdad sino una asignación de recompensas legítimas.... La noción de logro es ciega a todo menos al actor que logra, de modo que no nos dice nada sobre sus relaciones con otros o de su dependencia con respecto a ellos, sobre el libreto social que define el "logro" ni sobre los contextos de las oportunidades y las recompensas. ...El distanciamiento es ante todo un proceso sistémico que se desarrolla en sistemas preparados para forjar ganadores y perdedores -incluida la definición de lo que constituye "ganar"-, así como una distancia de recompensas y ventajas entre ellos. (Therborn, 2015, p. 60)
\end{abstract}

A través de los mecanismos señalados se genera una injusticia social dadas las condiciones de los que se encuentran en una posición de desventaja.

En lo que respecta a la explotación, Therborn (2015) establece que este mecanismo está asociado a una división por categorías entre personas superiores y personas inferiores, una distribución de élite en la cual las primeras extraen determinados beneficios mediante el trabajo de las segundas. En esta misma línea, Tilly (2000) manifiesta que la explotación se constituye en la captación del esfuerzo de un grupo inferior sin que el producto de dicho esfuerzo sea repartido o compartido. De acuerdo con Therborn (2015), la explotación como mecanismo reproductor de la desigualdad se encuentra asociada con la desigualdad existencial, al vulnerar las condiciones y virtudes de los individuos, haciendo que esta sea injusta.

Por otra parte, el tercer mecanismo que conduce a la desigualdad corresponde a la exclusión, el cual hace referencia al impedimento que presenta un individuo frente al acceso o progreso, generando, y a una división entre aquellos que pertenecen o no a un determinado grupo social (Therborn, 2015). Este mecanismo se encuentra asociado con el acaparamiento de oportunidades desarrollado por Tilly (2000), dado que este no genera un aprovechamiento del esfuerzo de un individuo o grupo de individuos, sino, por el contrario, genera exclusión a un recurso determinado. El último mecanismo analizado corresponde a la jerarquización, la cual produce desigualdad debido al carácter subordinado entre individuos, unos se encuentran ubicados en la escala superior y otros en la escala inferior, lo que implica la necesidad de establecer una organización (Therborn, 2015).

En este sentido, para Therborn (2015) es claro identificar que los mecanismos reproductores de desigualdad no son excluyentes en su actuación, por el contrario, se pueden combinar y desarrollar conjuntamente, lo cual podría acarrear una mayor desigualdad social, económica y cultural. Asimismo, afectan las condiciones de vida de los individuos al desmejorar sus niveles de salud, su autonomía, autoestima, y sus condiciones económicas (Therborn, 2015).

Así, de acuerdo con las diferentes posiciones de los teóricos analizados, se entenderá la desigualdad como un orden sociocultural que a través de diversos mecanismos reproduce las brechas sociales, impidiendo que todas las personas puedan llevar a cabo plenamente sus vidas.

A partir de lo anterior, en el campo de la educación superior, la desigualdad será entendida como aquel orden que involucra aspectos no solo de tipo económico, asociados con la capacidad de pago de los individuos, 
sino también con aspectos de tipo sociocultural, relacionados con el género, la pertenencia étnica, condiciones de discapacidad, que reproducen mecanismos como el acaparamiento de oportunidades, la jerarquización y el distanciamiento, a través de los cuales las diferentes brechas sociales se reproducen e impiden que las personas logren acceder a las mismas posiciones sociales en el sistema educativo y en la sociedad en general.

\section{¿Igualdad de oportunidades o igualdad de posiciones?}

Por otra parte, se enmarcan los estudios sociológicos relacionados con la identificación de los tipos de igualdad que debería garantizar la sociedad, si mediante diferentes intervenciones se garantiza una igualdad de oportunidades o, por el contrario, una igualdad de posiciones. Es así como se identifica que la tradición liberal ha estado enfocada en brindar mayor importancia a la igualdad de oportunidades, dejando de lado a aquella población que termina perdiendo de acuerdo con los resultados (Therborn, 2015).

Bajo ese análisis se encuentra el planteamiento establecido por Dubet (2011), quien enmarca dos perspectivas que surgen a partir de la concepción de justicia social, las cuales corresponden a la igualdad de oportunidades y a la igualdad de posiciones, cuyos propósitos se enfocan en reducir las inequidades sociales.

De acuerdo con Dubet (2011), la igualdad de oportunidades se basa en brindar a todos los individuos las mismas posibilidades para ocupar las posiciones de ventaja, basada en una concepción de mérito. Su argumento se fundamenta en establecer que los individuos son iguales en el punto inicial, eliminando las discriminaciones a las cuales pueden someterse, y permitiendo que sean distribuidos en las posiciones sociales de acuerdo con su esfuerzo individual o mérito (Dubet, 2011). No obstante, la igualdad de oportunidades manifiesta una problemática fundamental al direccionar la responsabilidad directa al individuo, "Después del nacimiento, o al menos después de los estudios, los individuos con iguales oportunidades quedan librados a su suerte, dependientes solo de su propio esfuerzo, cuyo resultado es responsabilidad exclusiva de ellos" (Therborn, 2015, p. 50).

Por otra parte, para Dubet (2011), al otorgar gran importancia al mérito se gesta una situación de competencia y discriminación, donde unos individuos poseen una gran ventaja, mientras que otros se encuentran en una situación perjudicial. La condición meritocrática bajo la cual se consolida la igualdad de oportunidades conlleva a un sentimiento de individualidad:

El modelo de igualdad de oportunidades parece decir siempre, al final, que uno no les debe nada a los demás y que es libre de toda deuda. Pero se olvida demasiado que las oportunidades individuales se benefician de las inversiones colectivas. (Dubet, 2011, p. 114)

Adicional al otorgamiento del mérito como fuente garante de acceder a las oportunidades, este tipo de igualdad no toma en consideración aquellas desigualdades sociales identificadas como inaceptables, por el contrario, presenta una tendencia a la aceptación y justificación de las mismas. La igualdad de oportunidades se apoya en aquellos programas focalizados para desarrollar su accionar, los cuales basan su implementación en la necesidad de reducir o controlar el gasto público, ya que los recursos son direccionados específicamente a la población pobre que requiere asistencia. Es decir, este tipo de programas son selectivos en cuanto al otorgamiento de los bienes y servicios públicos, por ende, requieren de una cantidad menor de recursos, sin embargo, su accionar puede "generar mecanismos de segmentación en la provisión de servicios que resultan a la postre funcionales a la reproducción de las desigualdades, en especial servicios sociales que están segmentados por su calidad" (Ocampo, 2012, p. 90).

Por su parte, los programas universalistas, al estar dirigidos al total de los ciudadanos, conducen a la reducción de las desigualdades sociales, y por ende requieren un mayor esfuerzo en materia de consecución de recursos públicos. Los programas universalistas generan una mayor distribución y progresividad del gasto público, permitiendo que todos los ciudadanos gocen de la plenitud de sus derechos al contar con una cobertura total. 
En algunas ocasiones, para garantizar la igualdad de oportunidades y el menor uso de recursos públicos se implementan no solo programas focalizados, sino que también se hace uso de subsidios a la demanda, en la que los usuarios sin capacidad de pago puedan acceder a los bienes y servicios ofertados en el mercado de acuerdo con su elección: "Al introducir los subsidios a la demanda se trata que los recursos estatales vayan dirigidos directamente a los usuarios pobres, mediante programas de focalización, para que a través del subsidio paguen la atención al servicio (Molina 1999, citado en Giraldo, 2007, p. 140).

El subsidio a la demanda opera bajo una lógica de competencia, ya que las entidades encargadas de la provisión de servicios sociales tienen que disputar en el mercado la demanda de los usuarios con el objetivo de obtener financiamiento. La puesta en marcha de este tipo de subsidios se fundamenta en la necesidad de generar eficiencia en la provisión de los servicios sociales y en el mejoramiento de la calidad; mientras que, por el contrario, el subsidio a la oferta opera bajo la dinámica del Estado, que es el encargado de administrar los recursos para la provisión de los bienes y servicios, sin tener en cuenta las lógicas del mercado ni la demanda directa de los usuarios.

Por su parte, la igualdad de posiciones basa su punto de acción en los lugares que estructuran la sociedad, en las posiciones que ocupan los diferentes individuos. El propósito fundamental de la igualdad de posiciones radica en la búsqueda de la reducción de desigualdades en relación con el nivel económico, y el acceso a bienes, servicios y niveles de vida, los cuales se ven determinados por las posiciones sociales en las que se ubican los individuos, dadas unas dotaciones educativas, etarias o de cualificación. De esta manera, "La igualdad de las posiciones busca entonces hacer que las distintas posiciones estén, en la estructura social, más próximas las unas de las otras, a costa de que entonces la movilidad social de los individuos no sea ya una prioridad" (Dubet, 2011, p. 11)

La igualdad de posiciones, para Dubet (2011), está bajo el dominio de diferentes tendencias, entre las que se encuentran la reducción de las distancias y la fijación de las posiciones. Es necesario reducir las desigualdades generadas entre las diversas posiciones, así como mantener los lugares que sean aceptables y se encuentren asegurados. Este modelo ha propendido por el aseguramiento y la redistribución, a través de la reducción en la brecha existente en los niveles de ingreso y en las condiciones de vida, garantizando a los más pobres sus derechos y una protección.

Evidenciando las diferencias entre la igualdad de oportunidades y la igualdad de posiciones, Dubet (2011) manifiesta la importancia de buscar la implementación de esta última, ya que considera que en la medida en que las desigualdades asociadas a las posiciones son reducidas, se facilitará o logrará una igualdad de oportunidades, donde existirá para los individuos una movilidad social ascendente. Para Dubet (2011), la igualdad de posiciones brinda apertura a una situación de autonomía de los individuos, ya que les permite escoger la vida que deseen, siendo que las posibilidades de elección no son excluyentes, por el contrario, son semejantes. En la medida en que las desigualdades sean menos marcadas, permitirán a los individuos su autonomía y su ascenso social, en comparación con aquella situación en la cual las desigualdades presentan una mayor distancia.

Para el caso colombiano, las condiciones que ha implementado el modelo neoliberal, enfocadas a la disminución del gasto público, el fortalecimiento de la inversión y la focalización en la provisión de bienes y servicios públicos, han conducido a que el Gobierno Nacional opte por el desarrollo de políticas enfocadas a la igualdad de oportunidades a través de la focalización en el otorgamiento de subsidios a la demanda materializados en créditos, que están asociados con la selectividad de los programas que tanto la focalización como el subsidio a la demanda priorizan y requieren. A través de los créditos se beneficia a población, considerada pobre, que de otra manera no tiene la posibilidad de acceder al mercado de bienes y servicios, dada su incapacidad de pago.

Tal es el caso de la educación superior, donde se brinda un subsidio a la demanda, para que los usuarios seleccionen los programas académicos y las instituciones de sus preferencias, ya que cuentan con la posibilidad de pago para acceder a ellas, de acuerdo con el crédito obtenido y con la capacidad de endeudamiento que este 
les otorga. Los programas de crédito educativo se han considerado instrumentos que permiten a determinado conjunto de la población (de manera selectiva) acceder a la educación superior. Dichos programas cuentan con un conjunto de parámetros específicos que determinan la población beneficiaria, ya sea a través de la capacidad de pago, es decir, de la condición socioeconómica de la misma, o del puntaje obtenido en pruebas de Estado. De tal manera, conocer la constitución de cada uno de los programas de crédito educativo establece una base fundamental para evidenciar sus objetivos, su alcance y su finalidad en materia de mejoramiento o desmejoramiento de la igualdad en el sistema de educación superior.

Este análisis teórico permitirá evidenciar bajo qué mecanismos se reproduce la desigualdad en el sistema de educación superior en Colombia, cómo se han desarrollado los programas de crédito educativo y subsidio a la demanda, es decir, si estos han optado por una postura de igualdad de posiciones o de oportunidades, $y$ si dicha postura condiciona el acceso de la población a la educación superior.

\section{Mejoramiento o deterioro de la igualdad en la educación superior en Colombia a través del crédito}

Los programas de crédito educativo aquí estudiados corresponden a ACCES, Ser Pilo Paga y Tú Eliges, los cuales desarrollan políticas de focalización y subsidio a la demanda, al establecer determinados cupos y condicionamientos para el otorgamiento de créditos tanto condonables como de financiación.

Los programas aquí analizados buscan favorecer la igualdad de oportunidades, al dar siempre relevancia al mérito individual como instrumento garante del acceso de la población al sistema de educación superior. Asimismo, demandan diferentes requisitos asociados a la selección de los potenciales beneficiarios, relacionados tanto con las condiciones socioeconómicas como con el nivel de logro académico alcanzado en las pruebas de Estado, el ser población indígena o perteneciente a una región del país (para el caso del programa Ser Pilo Paga), lo cual condiciona el ingreso de aquellos que no cumplen a cabalidad dichas condiciones. Adicionalmente, en algunos casos, la condición para el beneficiario depende de la capacidad de reflejar un nivel de endeudamiento, que le permita, posterior a la culminación del programa académico, ejecutar el pago correspondiente al crédito otorgado.

\section{Crédito ACCES}

Este tipo de crédito tuvo una vigencia de doce años, desde el 2003 hasta el primer semestre de 2015, de tal manera que la información analizada comprenderá dicho periodo. Los créditos otorgados bajo este programa se enfocaban en el financiamiento del $75 \%$ del total de la matrícula en formación universitaria para estratos 1 y 2, y el 50\% para estratos 3, 4, 5 y 6 . En lo correspondiente a programas de nivel técnico, tecnológico, Centros Regionales de Educación Superior y educación normalista, se cubría el 100\% de la matrícula.

\section{Nivel departamental}

De acuerdo con el número de beneficiarios del programa, se observa la elevada participación de departamentos como Antioquia, Atlántico, el Distrito Capital, Valle del Cauca y Santander, los cuales durante el periodo de análisis fueron los que presentaron la mayor cantidad de beneficiarios frente al total nacional (figura 1). Dentro de dichos departamentos sobresale el Distrito Capital, el cual tuvo un total de 78.587 beneficiarios, concentrando la mayor cantidad dentro del territorio nacional. Por su parte, los departamentos que presentaron una menor cantidad (figura 2) de beneficiarios corresponden a Vaupés (100), seguido de Guainía (199), Vichada (251) y Guaviare (866), para el periodo de referencia. 
$\mathrm{Al}$ analizar las condiciones de vida de los departamentos con menor número de beneficiarios, se identifica que presentan una elevada proporción de personas con Necesidades Básicas Insatisfechas (NBI), que ascienden para Vaupés al 54.77\%, para Vichada al 66.95\%, y para Guainía al 60.62\% (Departamento Administrativo Nacional de Estadística, 2016a). De tal manera, este comportamiento permite identificar que aquellas regiones en las cuales persisten condiciones de pobreza son las que menor oportunidad presentaron para la obtención de un crédito educativo.

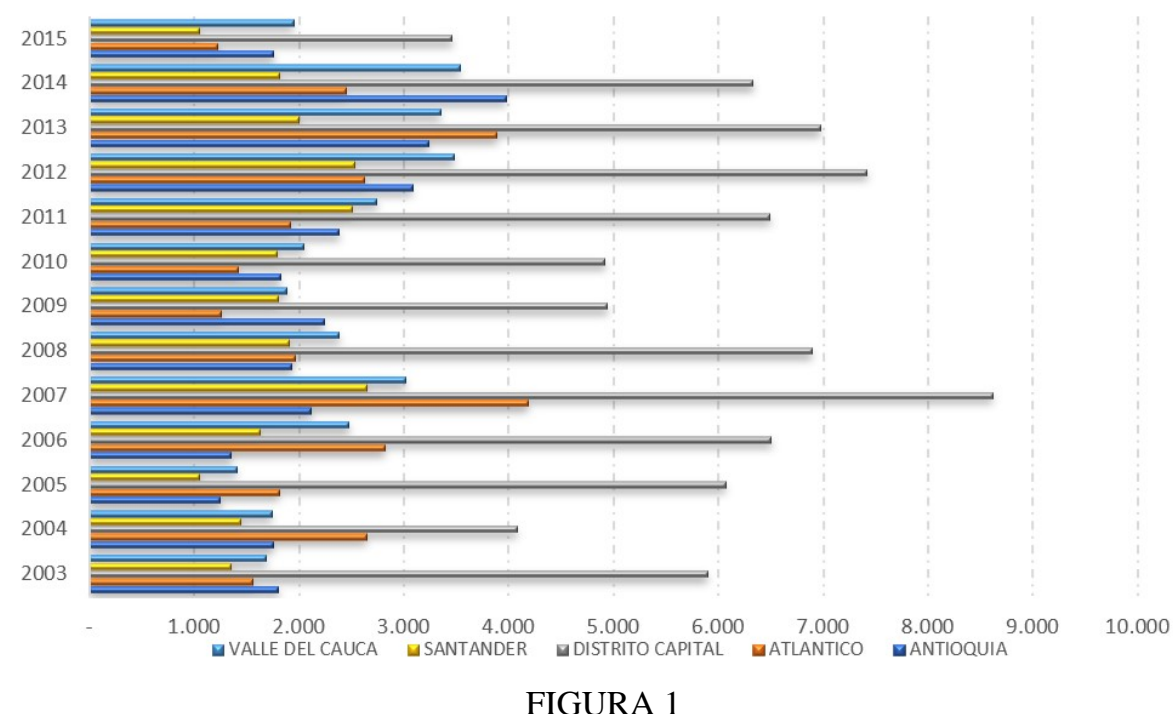

Departamentos que presentaron mayor número de beneficiarios por año elaboración propia a partir de la información estadística del Instituto Colombiano de Crédito Educativo y Estudios Técnicos en el Exterior (2016)

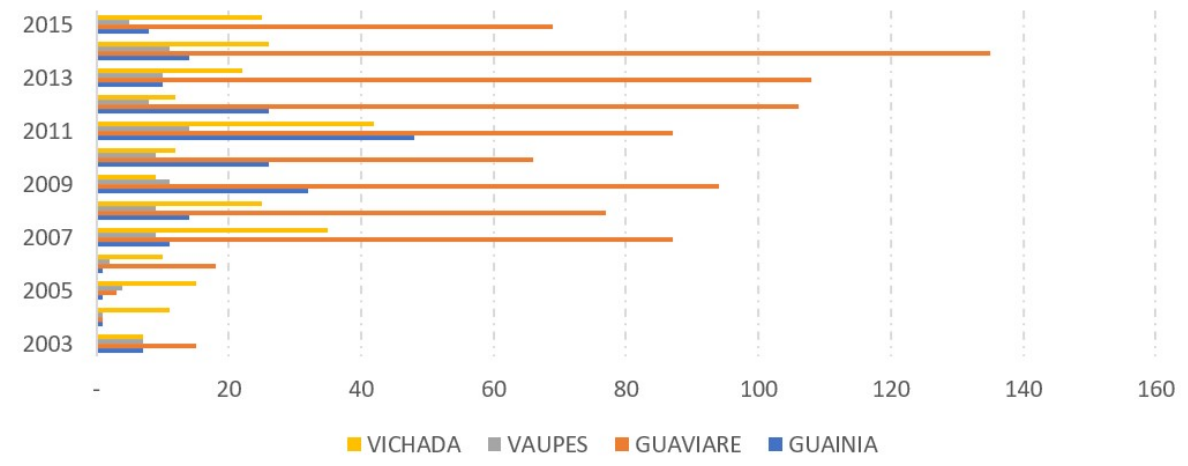

FIGURA 2

Departamentos que presentaron menor número de beneficiarios por año elaboración propia a partir de la información estadística del Instituto Colombiano de Crédito Educativo y Estudios Técnicos en el Exterior (2016)

Aun cuando existe una participación de beneficiarios en diferentes departamentos del país, la elevada concentración en el Distrito Capital es sinónimo de la centralización en el otorgamiento de créditos, lo cual refleja la dificultad presentada en la difusión de créditos en aquellas zonas donde la población estudiantil no puede acceder al sistema educativo. Este comportamiento pone al descubierto el deterioro de la igualdad que el programa ACCES genera al reproducir el mecanismo oportunidad establecido por Tilly (2000), denominado acaparamiento de oportunidades, debido a que en aquellas regiones donde existen mejores condiciones de vida se acaparan las pocas oportunidades otorgadas a través del crédito educativo, en comparación con las regiones de menores condiciones y calidad de vida, las cuales no cuentan con dicha capacidad, reproduciendo desigualdades regionales y sociales en el país. 


\section{Tipo de formación}

Durante el periodo de análisis se observa la prevalencia en la selección de la formación universitaria en comparación con los demás tipos de formación, aun cuando el Icetex (Instituto Colombiano de Crédito Educativo y Estudios Técnicos en el Exterior) estableció, a partir del Acuerdo No. 035 del 2007, la financiación del $100 \%$ de la matrícula para la educación técnica y tecnológica (Instituto Colombiano de Crédito Educativo y Estudios Técnicos en el Exterior, 2007). A lo largo del periodo, la formación universitaria presentó una participación del $77 \%$ de beneficiarios dentro de los tres tipos analizados. Por su parte, la educación tecnológica contó con una participación del 16\%, mientras que la técnica se ubicó en el 7\%, tal como lo indica la figura 3.

A pesar de que la educación tecnológica presenta un crecimiento de la población beneficiaria a partir del año 2011 (figura 4), existe una tendencia creciente a financiar la formación universitaria, ya que esta refleja mejores beneficios futuros frente a la técnica y tecnológica.

A su vez, existe una elevada propensión a ingresar a la educación universitaria; de acuerdo con el Ministerio de Educación Nacional (2016a), la participación de la formación universitaria dentro de la matrícula total se ha ubicado por encima del 60\% desde el año 2007 hasta el año 2015; igualmente, el porcentaje de recién graduados que se vinculan al sector formal es considerablemente superior para el nivel universitario, ubicándose para el 2014 en el $80.7 \%$, mientras que para la formación técnica y tecnológica dicho porcentaje se ubicó en $66.5 \%$ y $72.2 \%$, respectivamente.

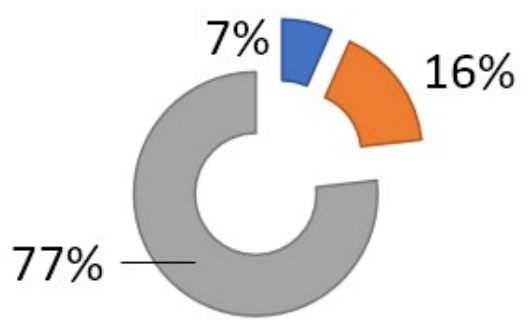

-TÉCNICA

$\square$ TECNOLÓGICA

UNIVERSITARIA

FIGURA 3

Participación de beneficiarios por tipo de formación, para el periodo 2003 a primer semestre de 2015 elaboración propia a partir de la información estadística del Instituto Colombiano de Crédito Educativo y Estudios Técnicos en el Exterior (2016)

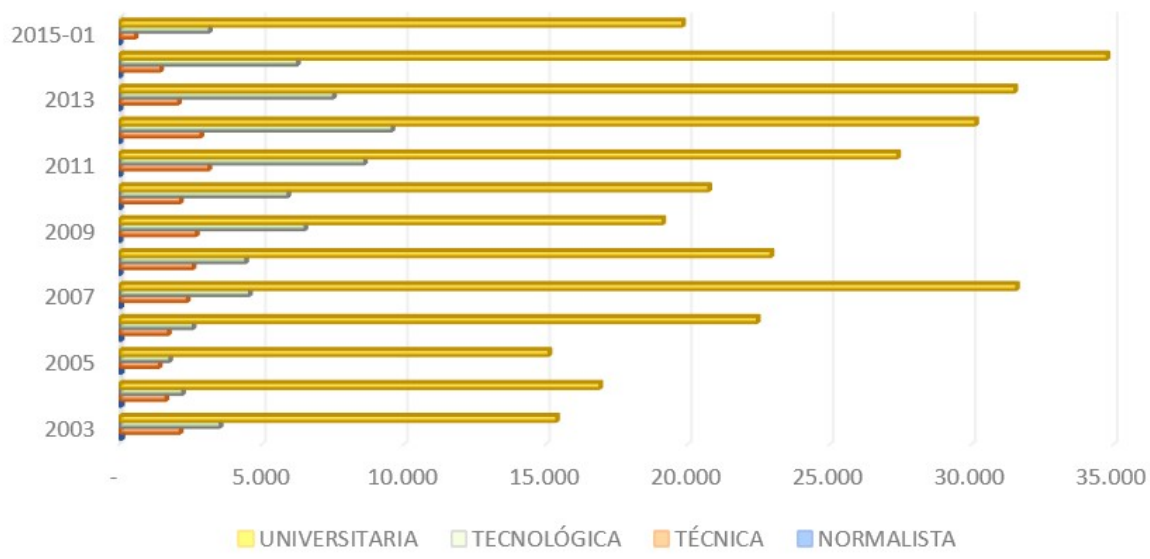

FIGURA 4

Total de beneficiarios por tipo de formación y año elaboración propia a partir de la información estadística del Instituto Colombiano de Crédito Educativo y Estudios Técnicos en el Exterior (2016) 
La ausencia en la promoción de programas de formación técnica y tecnológica, sumada a los diferenciales salariales percibidos frente a la formación universitaria, conduce a que cada vez más sean elegidos estos últimos como la mejor alternativa de progreso y movilidad social. De acuerdo con Gómez (2015), la estructura característica de la oferta de educación superior presenta una fuerte tendencia hacia la formación universitaria tradicional, subvalorando las demás instituciones de educación superior que ofrecen programas técnicos y tecnológicos; asimismo, la demanda de educación superior se concentra en la formación universitaria tradicional.

Por otra parte, al analizar el porcentaje de población por fuera del sistema (Ministerio de Educación Nacional, 2016a), se observa (figura 5) que departamentos como Guainía, Guaviare, Vaupés y Vichada fueron los que mayor porcentaje reportaron, ubicándose en $87.90 \%, 87.31 \%, 93.78 \%$ y $92.39 \%$, para el 2011, respectivamente; en comparación con el nivel nacional que se registró en el 59.62\%.

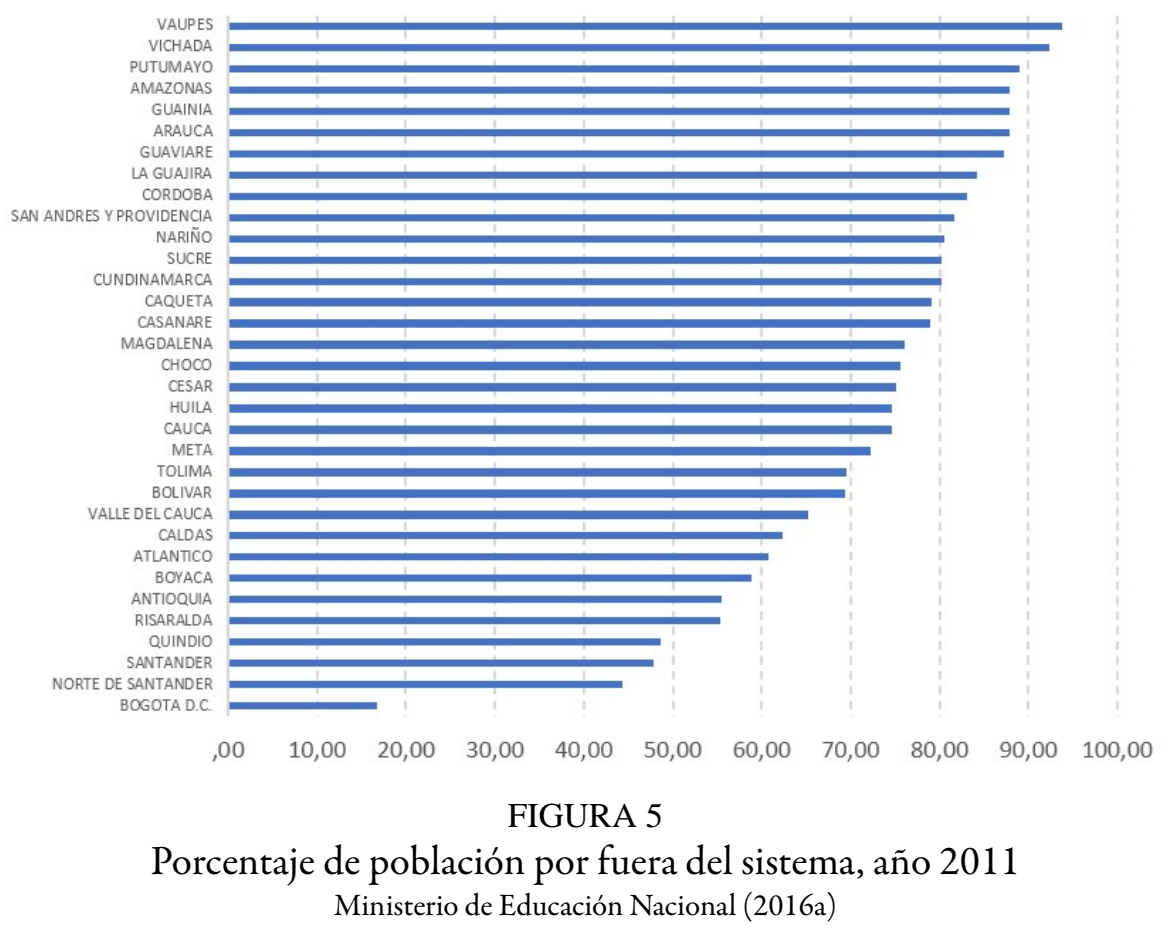

De tal manera, este comportamiento en el total de población que se encuentra por fuera del sistema permite analizar que este tipo de programa focalizado no ha beneficiado al total de bachilleres provenientes de regiones con elevada proporción de personas bajo NBI, ni ha fortalecido la inclusión de la formación universitaria en este tipo de regiones.

\section{Estrato socioeconómico}

Este programa tuvo dentro de sus objetivos principales contribuir a la financiación de la educación superior de la población en diferentes estratos socioeconómicos. Sin embargo, el mayor nivel de financiación se dirigió a población de estratos bajos. De esta manera, dentro del total de beneficiarios se observa que el estrato 2 es el que presenta la mayor cantidad, con un total de 199.833 beneficiarios, seguido por el estrato 1, con 119.864, con una participación de $49.7 \%$, y $29.8 \%$, respectivamente, dentro del total de estratos. Por su parte, el estrato 6 presentó una participación del $0.3 \%$ frente al total, tal como lo muestra la figura 6 . 
$3 \%$

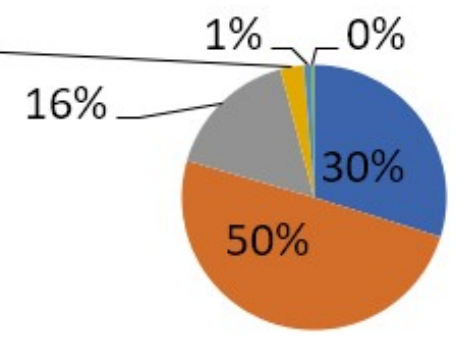

Estrato 1

Estrato 2

Estrato 3

Estrato 4

Estrato 5

Estrato 6

FIGURA 6

Distribución de beneficiarios por estrato socioeconómico elaboración propia a partir de la información estadística del Instituto Colombiano de Crédito Educativo y Estudios Técnicos en el Exterior (2016)

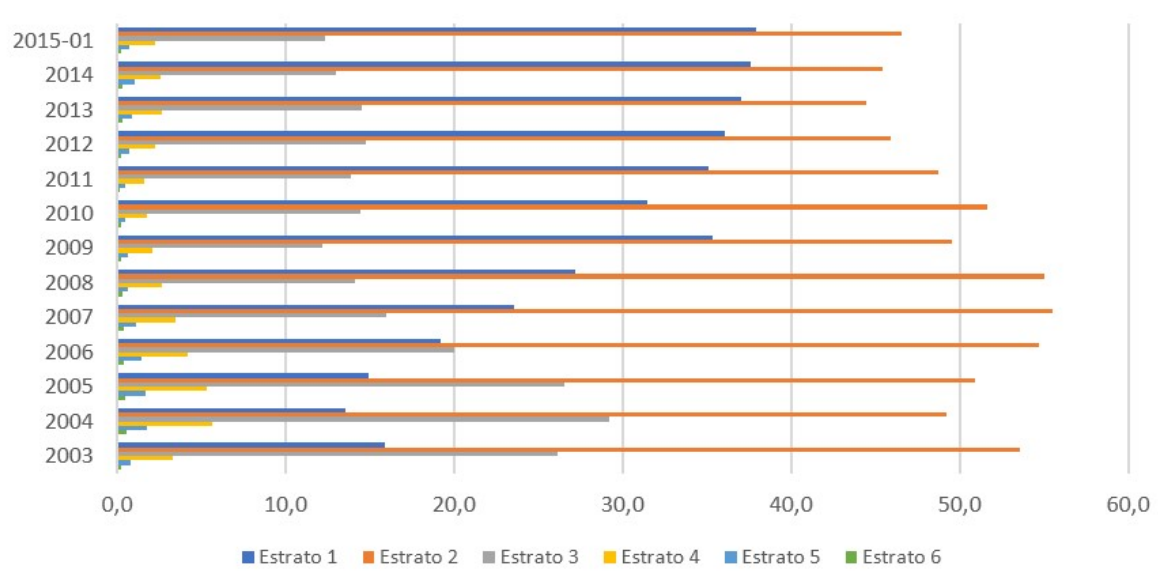

FIGURA 7

Total de beneficiarios por estrato socioeconómico y año elaboración propia a partir de la información estadística del Instituto Colombiano de Crédito Educativo y Estudios Técnicos en el Exterior (2016)

Con la puesta en marcha del programa ACCES se observa la tendencia creciente por la financiación de la educación superior privada por parte de estudiantes de estratos socioeconómicos desfavorecidos, dado que la financiación de la matrícula a través de un crédito educativo se consolida como la única opción para acceder al sistema de educación superior. A su vez, este comportamiento es reforzado por el creciente desfinanciamiento de la educación pública, que dificulta lograr la universalidad en el acceso al sistema de educación superior, brindando cada vez más prelación a la privatización como garante del acceso, lo cual reduce las posibilidades de disminuir las desventajas existentes (Mora, 2016a).

Por otra parte, puede indicarse que este tipo de programa presentó una tendencia de focalización de créditos para población vulnerable, es decir, optó por una discriminación positiva dirigida a los estratos socioeconómicos más bajos; no obstante, su mismo carácter focalizado permitió que se reprodujera el mecanismo de acaparamiento de oportunidades, debido a que los diferentes requisitos exigidos condujeron a una lógica de discriminación, beneficiando a las personas que contaron con algún tipo de ventaja frente a los peor situados en materia socioeconómica, y específicamente a aquellos capaces de evidenciar un nivel de endeudamiento suficiente, o la disponibilidad de un codeudor. 


\section{Género}

El comportamiento de los beneficiarios por género (figuras 8 y 9), se aprecia direccionado hacia la población femenina, presentando la mayor cantidad de beneficiarios durante el periodo, ascendiendo a 224.395 beneficiarias, con una participación dentro del total del 55.8\%. Por su parte, la población masculina participó con el $44.2 \%$ con un total de 177.865 beneficiarios

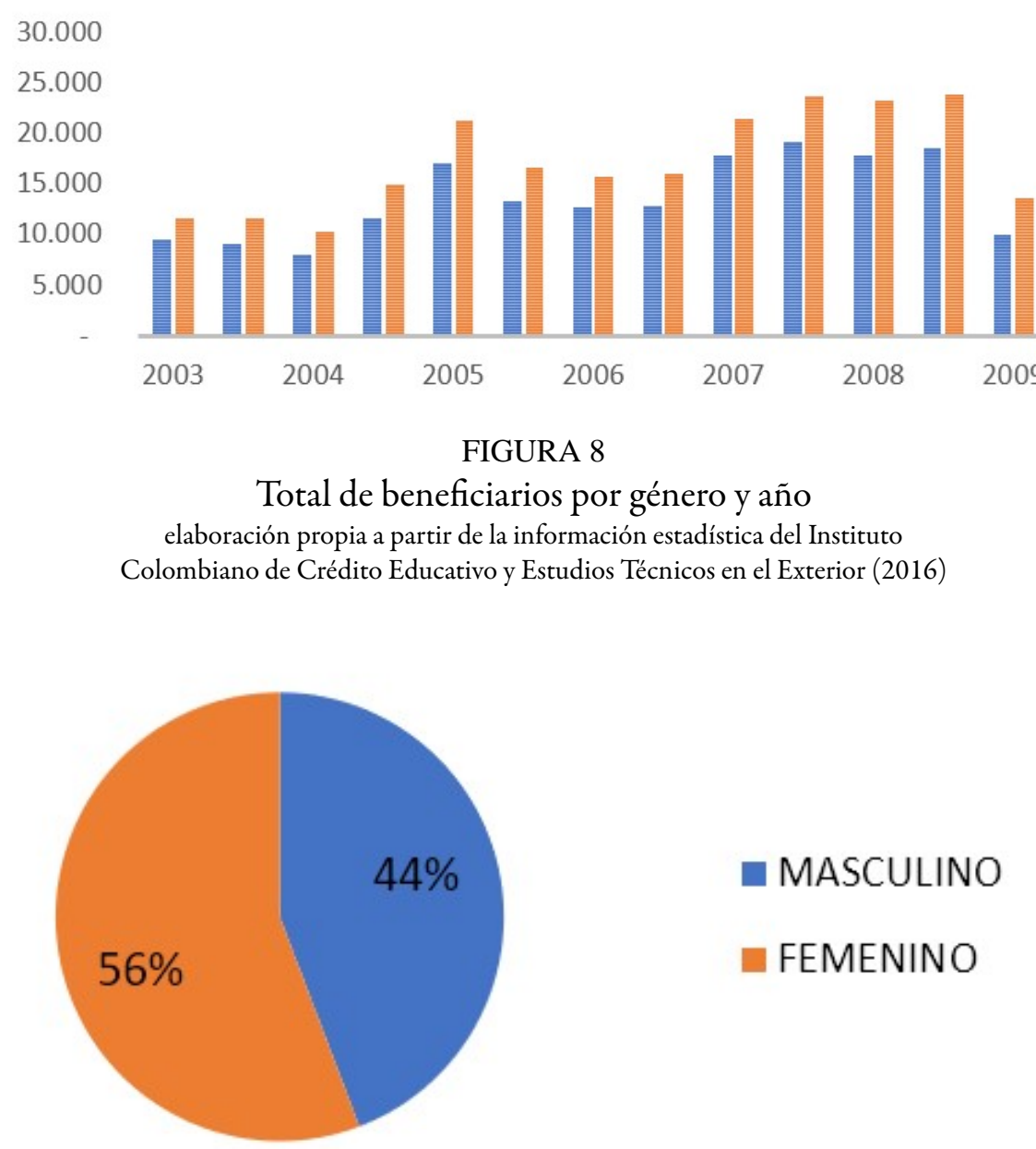

FIGURA 9

Distribución de beneficiarios por género elaboración propia a partir de la información estadística del Instituto Colombiano de Crédito Educativo y Estudios Técnicos en el Exterior (2016)

El valor total de la financiación de los créditos del programa para la población femenina se ubicó en $\$$ 417.150.855.576, con una destinación del 55.54\% sobre el total de recursos. Por su parte, el valor de los créditos asignados a la población masculina ascendió al 44.46\% del total, con un valor de \$333.993.147.885.

\section{Tipo de población}

En el marco de las acciones afirmativas establecidas en el programa, se encontraron beneficiarios caracterizados por su pertenencia étnica $\left[{ }^{2}\right.$, sin embargo, la información se encuentra disponible desde el año 
2009. De acuerdo con la figura 10, la población que presentó una mayor cantidad de beneficiarios durante el periodo 2009-2015 correspondió a la indígena, con un total de 12.641 beneficiarios, seguida de la población afrocolombiana, con un total de 4325, y la población raizal, con 348 beneficiarios. Para el año 2014, se presentó la mayor cantidad de beneficiarios frente a todo el periodo de análisis, tanto para la población indígena como para la afrocolombiana, reportando un total de 3581 y 1318 beneficiarios, respectivamente.

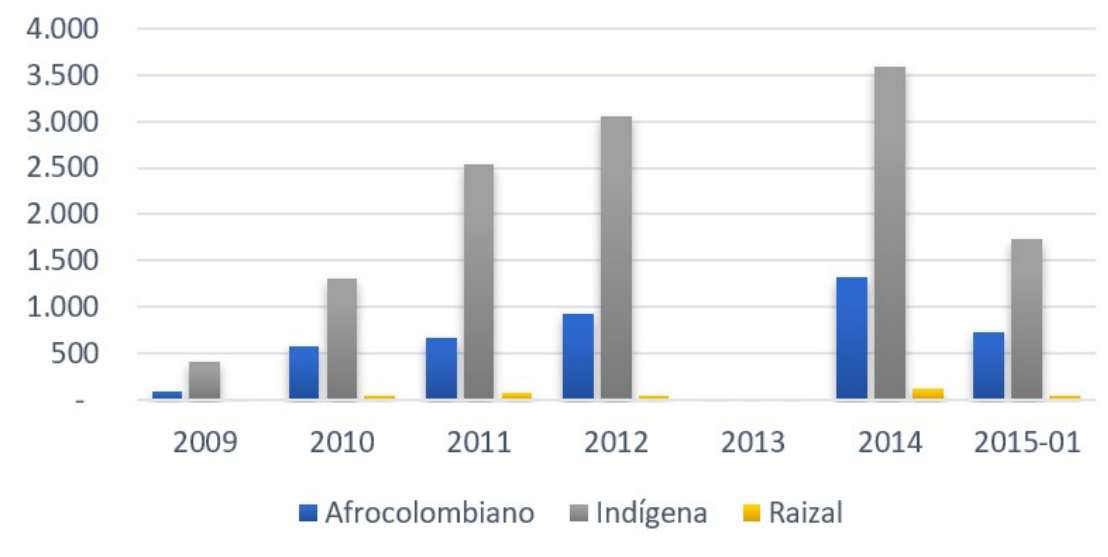

FIGURA 10

Total de beneficiarios por tipo de población y año

elaboración propia a partir de la información estadística del Instituto

Colombiano de Crédito Educativo y Estudios Técnicos en el Exterior (2016)

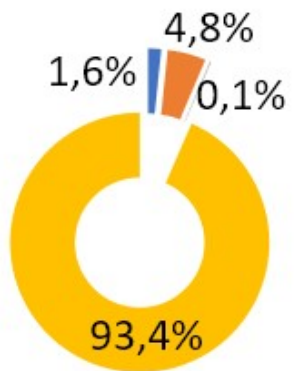

\section{Afrocolombiano \\ Indígena \\ Raizal \\ Demás beneficiarios}

\section{FIGURA 11}

Participación por grupo étnico dentro del total de beneficiarios en el periodo 2009 a primer semestre de 2015

elaboración propia a partir de la información estadística del Instituto Colombiano de Crédito Educativo y Estudios Técnicos en el Exterior (2016)

De acuerdo con el total de beneficiarios para el periodo 2009 hasta primer semestre de 2015, la población indígena contó con una participación del $4.8 \%{ }^{3}$, seguida de la población afrocolombiana con el $1.6 \%$ y la raizal con el $0.1 \%$ (figura 11 ).

De acuerdo con el Icetex, para el año 2012 y 2013 se beneficiaron un total de 2336 personas pertenecientes al programa Red Unidos del Gobierno Nacional, y hubo un total de 86 beneficiarios reinsertados. 


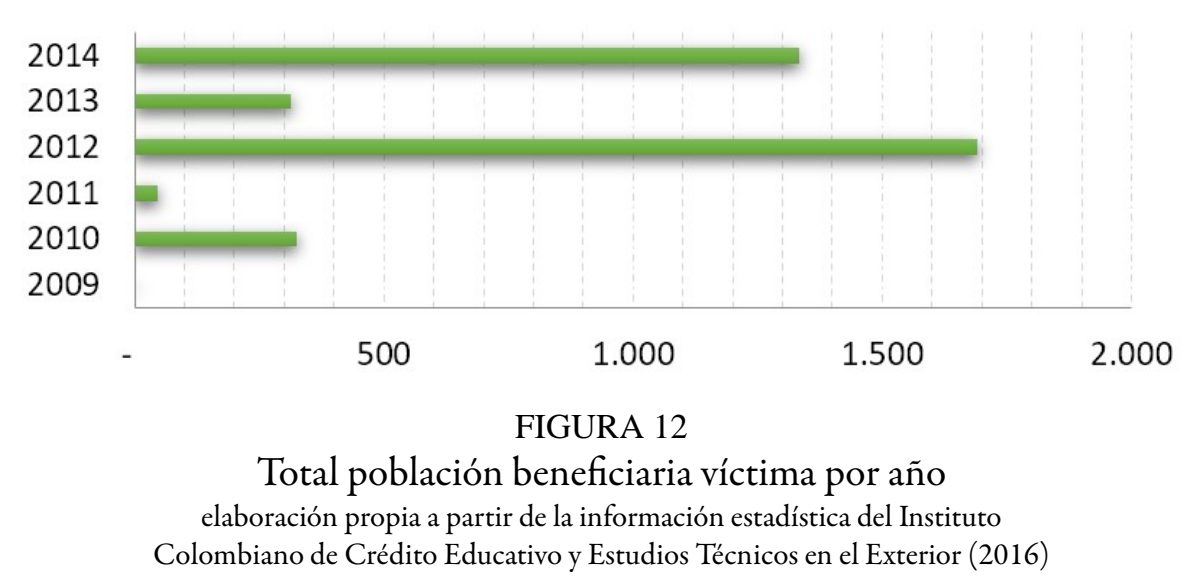

Asimismo, se brindaron créditos a la población víctima de la violencia para los años 2010 a 2014, la cual constituyó un total de 3708 beneficiarios, con una participación dentro del total del $0.9 \%$; y para la población en condición de discapacidad se cuenta con información para el primer semestre de 2015, donde se brindaron un total de 52 créditos, que representaron el $0.22 \%$ frente al total del mismo año.

\section{Programa Ser Pilo Paga}

El gobierno nacional, en cabeza del Ministerio de Educación, ha generado como alternativa de solución el programa denominado "Ser Pilo Paga", el cual tiene como propósito posibilitar el acceso a la educación superior a aquellos estudiantes de escasos recursos, cuyos puntajes en la prueba Saber 11 hayan sido sobresalientes, y se encuentren incluidos en el Sisbén. Según el Ministerio de Educación Nacional (2016b), el planteamiento de este programa se encuentra adicionalmente direccionado al mejoramiento de la excelencia de la educación superior y a disminuir las brechas de acceso y equidad, para que se garantice la igualdad de oportunidades.

En este sentido, el beneficio concedido a los participantes del programa gira en torno al otorgamiento de créditos condonables del $100 \%$ de las matrículas, siempre y cuando el estudiante culmine satisfactoriamente sus estudios y obtenga el titulo correspondiente; así mismo, el beneficio incluye la asignación de una cuantía de dinero para la manutención del estudiante, dependiendo de su condición. La primera versión del programa fue puesta en marcha en octubre del 2014, y dada su acogida fue desarrollada la segunda versión en el 2015.

\section{Nivel departamental}

Los tres departamentos por institución educativa que presentaron mayor cantidad de beneficiarios durante la vigencia del programa, año 2014 (figura 13), corresponden al Distrito Capital, con 3739, Antioquia con 1889 y Atlántico con 1104, cuyas participaciones fueron $36.9 \%, 18.6 \%$ y $10.9 \%$, respectivamente 
Ser Pilo Paga 1

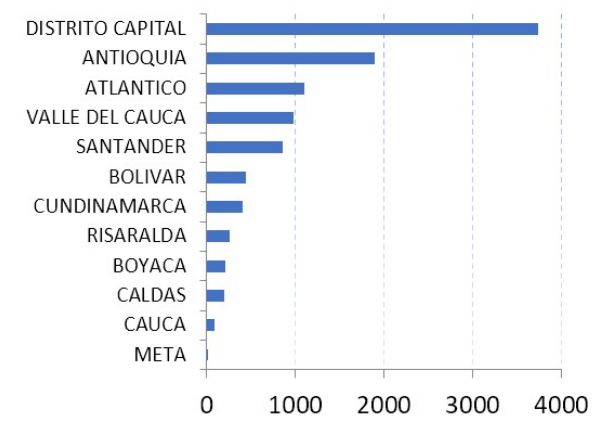

Ser Pilo Paga 2

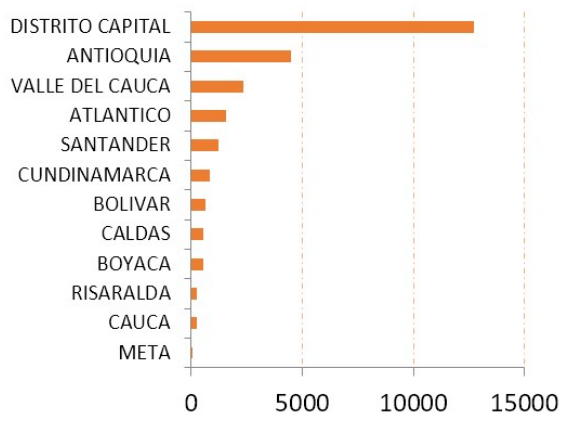

FIGURA 13

Número de beneficiarios a nivel departamental por Institución de Educación Superior Instituto Colombiano de Crédito Educativo y Estudios Técnicos en el Exterior (2016)

De acuerdo con el comportamiento departamental, la concentración del mayor número de beneficiarios en los departamentos señalados podría ser consecuencia de la determinación, por parte del Gobierno Nacional, de centralizar la selección de programas en aquellas instituciones de educación superior acreditadas como de alta calidad, las cuales, en su mayoría, se encuentran en ciudades como Bogotá, Medellín y Barranquilla, y no corresponden al total de las universidades públicas ubicadas en diferentes zonas del territorio nacional.

Esta priorización de las instituciones de educación superior que se encuentran actualmente certificadas como de alta calidad corresponde a una manifestación de la imposibilidad que presenta este programa frente al mejoramiento de la igualdad en el sistema de educación superior en Colombia, dado que gesta un escenario para que el mecanismo de desigualdad denominado jerarquización se desarrolle. A través de este programa se consolida una barrera que divide aquello a lo cual se considera superior, como son las instituciones de educación superior universitarias, específicamente aquellas de alta calidad, y segrega aún más las instituciones no certificadas de alta calidad, tanto universitarias como técnicas profesionales y tecnológicas, condicionando y reproduciendo las brechas sociales entre quienes pueden acceder a estas mejores instituciones y quienes no logran obtener dicha oportunidad y deben optar por aquellas de baja calidad. En lugar de propender por el mejoramiento de la calidad en las instituciones de educación superior públicas que aún no cuentan con dicha calificación, se establece una jerarquía entre las mejores y peores, presentando aún más condiciones de desigualdad entre aquellos que logran ser beneficiarios y quienes tienen que optar a las instituciones no certificadas de alta calidad (Gómez, 2015).

Ser Pilo Paga 1

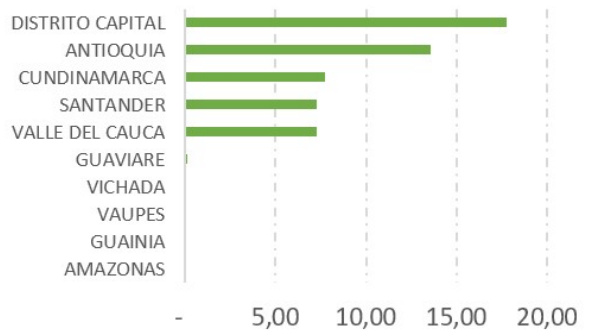

Ser Pilo Paga 2

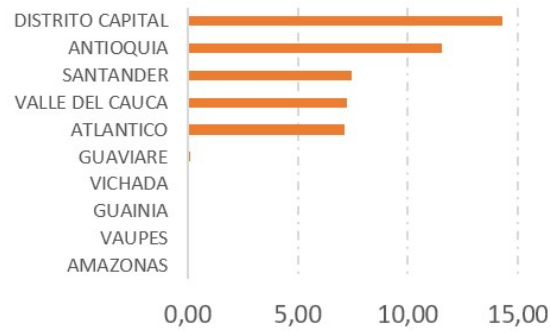

FIGURA 14

Participación de beneficiarios por departamento según procedencia de la familia

elaboración propia a partir de la información estadística del Instituto

Colombiano de Crédito Educativo y Estudios Técnicos en el Exterior (2016) 
Adicionalmente, al analizar los departamentos de procedencia de los beneficiarios, puede evidenciarse que para la primera y segunda versión del programa, el Distrito Capital, Antioquia y Santander fueron los departamentos que mayor participación presentaron dentro del total de beneficiarios, la cual ascendió al $17.8 \%, 13.6 \%$ y $7.3 \%$ para la primera versión, y al $14.3 \%, 11.5 \%$ y $7.4 \%$ para la segunda, respectivamente; mientras que los departamentos que menor participación tuvieron frente al total correspondieron a Amazonas y Guainía, con un total del $0.03 \%$, seguidos de Vaupés, con una participación del $0.04 \%$ para la primera versión; y ubicándose en $0.1 \%$ para Amazonas, 0.02\% para Vaupés y 0.06\% para Guainía en la segunda versión.

Esta situación es determinante al momento de analizar el porcentaje de población que se encuentra por fuera del sistema, dado que para estos departamentos ascendió para el 2011, año con última información, al $87.92 \%$, 93.78\% y $87.90 \%$, respectivamente. A su vez, al realizar el análisis por NBI, se puede identificar que aquellos departamentos por procedencia de la familia con menor número de beneficiarios son los que presentan una mayor proporción de personas bajo insatisfacción de necesidades, ubicándose para Amazonas en el $44.41 \%$, para Guainía en el $60.62 \%$ y para Vaupés en el $54.77 \%$. Esta situación evidencia las brechas regionales presentes frente a las posibilidades de obtener un cupo en una institución de educación superior a través de este programa, dado que la menor cantidad de beneficiarios se ubica en departamentos con elevadas necesidades básicas insatisfechas, lo cual puede ser un determinante frente al rendimiento académico obtenido en las pruebas de Estado y sus posibilidades de acceder al sistema de educación superior.

\section{Tipo de formación}

Frente al tipo de formación, se observa igualmente la relevancia brindada a la formación universitaria, sin considerar la formación técnica y tecnológica sustancial, necesaria para el fortalecimiento del sistema. Tanto para la primera como para la segunda versión del programa se identifica la elevada participación de beneficiarios en la formación universitaria, la cual se ubica en el 99\%. Por el contrario, la educación técnica presentó una participación de $0.03 \%$, y la tecnológica del $1.0 \%$ frente a la primera versión, y para la segunda versión de $0.01 \%$ y $0.27 \%$, respectivamente.

Ser Pilo Paga 1

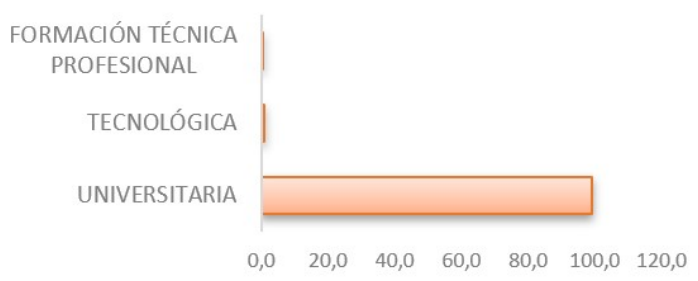

Ser Pilo Paga 2

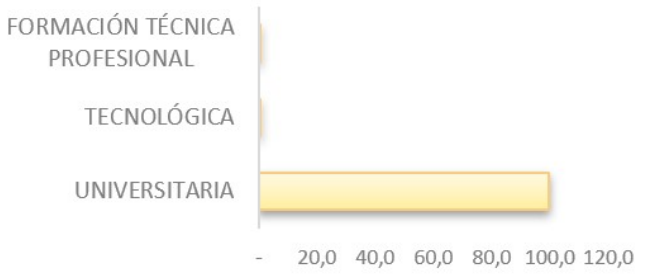

FIGURA 15

Porcentaje de participación de beneficiarios por tipo de formación elaboración propia a partir de la información estadística del Instituto Colombiano de Crédito Educativo y Estudios Técnicos en el Exterior (2016)

Al presentar la mayor demanda en el tipo de formación universitario, se reafirma y consolida una segregación de programas de formación técnica y tecnológica, que es concebida como una opción de bajo progreso social. Nuevamente, con este programa se refuerza la pirámide estructural de la educación superior en el país, consolidando efectos negativos como el establecido por Gómez (2015), relacionado con el imaginario social en el cual la universidad es la institución de mayor deseo, mientras que las demás representan aquella segunda opción, de baja calidad y posición social, dirigida a estudiantes de bajos recursos. 
De tal manera, la igualdad de oportunidades, prioritaria en los programas focalizados, conduce, a través del mérito individual, al crecimiento en la selección de la universidad privada, lo cual reproduce y mantiene la jerarquización entre instituciones de educación superior (Gómez, 2015).

Este tipo de programas deterioran la igualdad en el sistema de educación superior, dado que no eliminan o reducen el mecanismo de desigualdad de acaparamiento de oportunidades, debido a que la población beneficiaria acapara oportunidades en la formación universitaria a través de la concepción de mérito y esfuerzo individual, dejando a la población que no cumple con los requisitos establecidos de "pilo y pobre" la formación técnica y tecnológica de bajo costo y baja retribución económica en el futuro.

El acaparamiento de oportunidades por parte de los "pilos" hará que estos reciban mejores beneficios económicos y sociales en comparación con la población que no logró dicho beneficio ni tuvo la posibilidad de acceder a la educación superior, teniendo que dirigir su demanda a la formación técnica o tecnológica, reproduciendo así brechas de desigualdad entre beneficiarios y no beneficiarios; una vez que la formación universitaria en el país cuenta con mejor posicionamiento y prestigio que los demás tipos.

\section{Tipo de Institución de Educación Superior}

Con la puesta en marcha de este programa de crédito educativo se presenta un comportamiento privatizador de la educación superior, debido a que la proporción de instituciones de educación superior públicas dentro del total de las acreditadas como de alta calidad es considerablemente baja. Dentro del total de las 32 públicas en el país, tan solo se contemplan 14 de ellas para el programa de crédito, puesto que su selección esta soportada bajo la premisa de la certificación de alta calidad que poseen; es decir, dentro de las 39 instituciones de educación superior acreditadas para el programa, tan solo las instituciones públicas representan el 36\%.

TABLA 1

Total de beneficiarios por tipo de Institución de Educación Superior elaboración propia a partir de la información estadística del Instituto Colombiano de Crédito Educativo y Estudios Técnicos en el Exterior (2016).

\begin{tabular}{cccc}
\hline \multicolumn{2}{c}{ Ser Pilo Paga 1 } & \multicolumn{2}{c}{ Ser Pilo Paga 2 } \\
\hline $\begin{array}{c}\text { Tipo de } \\
\text { institución }\end{array}$ & $\mathbf{N}^{\circ}{ }^{\circ}$ beneficiarios & $\begin{array}{c}\text { Tipo de } \\
\text { institución }\end{array}$ & N. ${ }^{\circ}$ beneficiarios \\
\hline Pública & 1746 & Pública & 2151 \\
\hline Privada & 8395 & Privada & 10.559 \\
\hline
\end{tabular}




\section{Ser Pilo Paga 1 y 2}

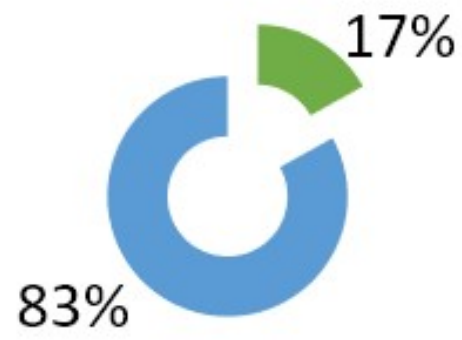

\section{PÚBLICA}

PRIVADA

FIGURA 16

Distribución de beneficiarios por tipo de Institución de Educación Superior

elaboración propia a partir de la información estadística del Instituto

Colombiano de Crédito Educativo y Estudios Técnicos en el Exterior (2016)

Del total de beneficiarios para los programas, se observa que las instituciones de educación superior públicas han recibido un total de 3897 de ellos, correspondientes al 17\% del total, mientras que las instituciones de educación privada cuentan con un total de beneficiarios que asciende a 18.954, representando el $82 \%$ (tabla 1 y figura 16). De acuerdo con los beneficiarios recibidos, se considera que las instituciones de educación superior privadas son las que perciben la mayor cantidad de recursos del programa, sin ningún tipo de contribución o retribución especial, y sin contar con la necesidad de obtener apoyo financiero, como en el caso de las instituciones públicas.

De acuerdo con el Icetex y el Ministerio de Educación Nacional (MEN), el valor del programa en su primera versión ascendió a $\$ 155.000$ millones, cubriendo un total de 10.141 beneficiarios, es decir, que el costo promedio por estudiante financiado a través del programa se ubicó en \$15.284.489. De acuerdo con el Consejo Nacional de Educación Superior (2014), para el año 2012, el costo promedio por estudiante financiado por el Gobierno Nacional para instituciones universitarias ascendió a 2386 dólares, los cuales equivalían, a tasa de enero de 2014, a \$ 4.609 .752 (Mora, 2016b).

Por consiguiente, al comparar los costos asumidos por el programa y aquellos asumidos por el Gobierno Nacional para la formación universitaria, puede analizarse la existencia de una diferencia aproximada de $\$ 10.674 .737$. Esta situación es reflejo de la gran cantidad de recursos destinados al programa, los cuales, como se indicó previamente, están dirigidos en su mayoría a la financiación de la educación superior privada, permitiendo el ingreso de estudiantes, pero en una menor proporción de la que podría ingresar a la educación superior pública; dejando de lado la situación estructural de financiación que presentan las 32 instituciones de educación superior públicas del país. 

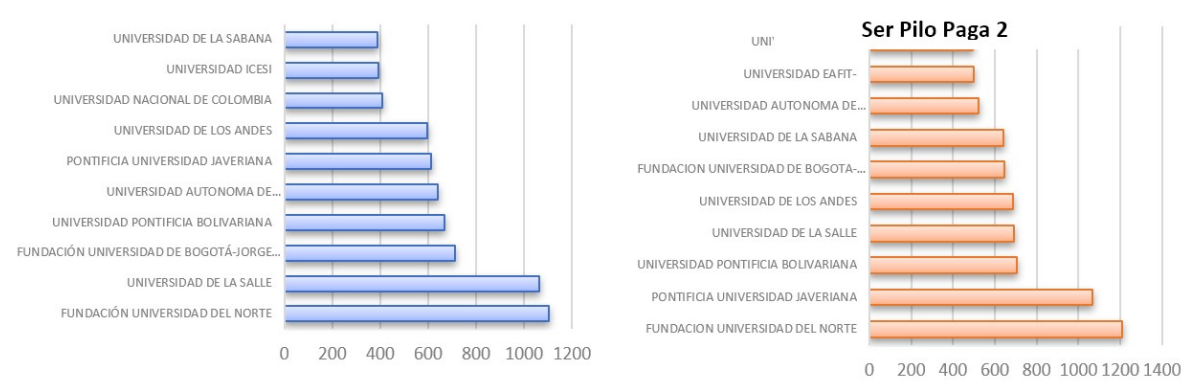

FIGURA 17

Principales Instituciones de Educación Superior que recibe la mayor cantidad de beneficiarios elaboración propia a partir de la información estadística del Instituto Colombiano de Crédito Educativo y Estudios Técnicos en el Exterior (2016)

De acuerdo con la figura 17, se observa que la mayor cantidad de beneficiarios se encuentran en las IES privadas (caracterizadas por su elevado nivel de matrícula), por lo cual estas acaparan la mayor cantidad de recursos provenientes del programa. Esta situación conlleva a que la educación superior, fomentada por programas como Ser Pilo Paga, se oriente a la financiación de la educación superior privada, debido a la poca participación de instituciones de educación superior de carácter público; $\mathrm{y}$, adicional a ello, a la dificultad que presentan los estudiantes, que han recibido educación básica y media de baja calidad, frente a la obtención de puntajes necesarios en los exámenes de ingreso en instituciones públicas.

En esta misma orbita se encuentra el estudio desarrollado por Mora (2015), en el cual se establece que la financiación brindada al programa podría haber beneficiado aproximadamente a 30.000 estudiantes en las universidades pertenecientes al Sistema Universitario Estatal. Asimismo, determina que el valor asignado a las universidades privadas, quienes son las que presentan mayor número de beneficiarios, podría financiar 15 universidades públicas ${ }^{4}$, dado que el monto percibido por las primeras es mucho mayor en comparación con las transferencias destinadas por el Gobierno Nacional a cada una de las universidades públicas. De acuerdo con el Observatorio de la Universidad Colombiana, dentro de los recursos de Ser Pilo Paga, el 98\% se han dirigido al pago de instituciones de educación superior privada, las cuales abarcan el mayor número de beneficiarios dentro del total (Observatorio de la Universidad Colombiana, 2016).

De acuerdo con Gómez (2015), al direccionar la financiación de la educación a unas pocas instituciones se desconoce la necesidad de financiar a otras instituciones del sector oficial, cuyo carácter es no universitario, tal es el caso de aquellas técnicas o tecnológicas que contribuyen a la ampliación de la cobertura, a la reducción de la centralización de oportunidades y a la diversificación de programas.

\section{Estrato socioeconómico}

Como se indicó, el programa cuenta con una serie de requisitos para la adjudicación del crédito condonable, uno de ellos se relaciona con el puntaje del Sisbén obtenido. Esto con el objetivo de brindar prioridad a aquella población de escasos recursos o bajo nivel socioeconómico, que no cuenta con la capacidad de pago de una matrícula universitaria.

De acuerdo con el Icetex, para el programa en su primera versión hubo un total de 10.141 beneficiarios y un total de 12.710 beneficiarios correspondientes a la segunda. Para ambas versiones, los estratos 1, 2 y 3 presentaron la mayor cantidad de beneficiarios dentro del total. En la primera versión, la mayor cantidad de beneficiarios se encontró ubicada en el estrato 2, el cual ascendió a 4591 beneficiaros, seguido del estrato 1 con 3955 y del estrato tres con 1534. Por su parte, para la segunda versión, la mayor cantidad de beneficiarios correspondió al estrato 1, con un total de 5642, para el estrato 2 este valor ascendió a 5181, y para el estrato 
3 se ubicó en 1807 beneficiarios. Para ambos programas la participación del estrato 1 y 2 ascendió al 42\%, y para el estrato 3 al $14.6 \%$
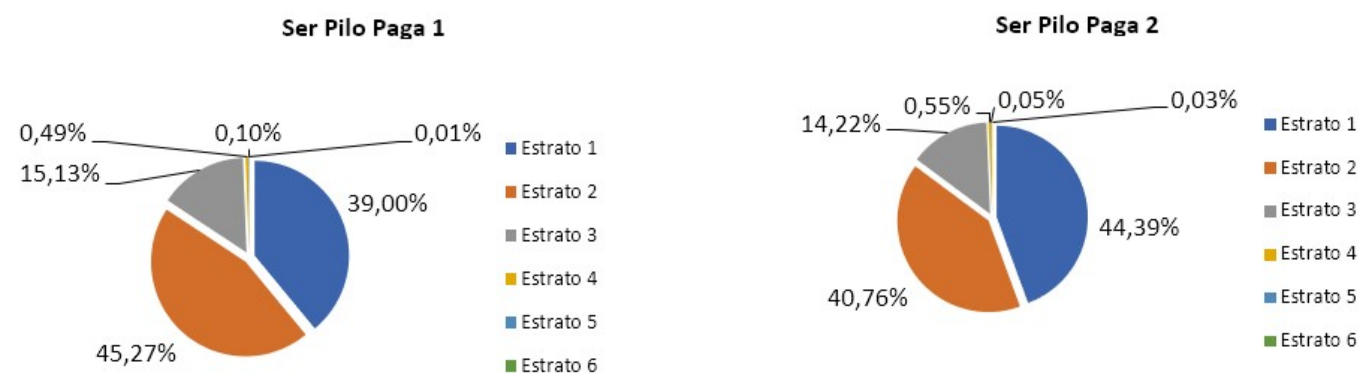

FIGURA 18

Participación de beneficiarios Ser Pilo Paga 1 y Ser Pilo Paga 2 por estrato

elaboración propia a partir de la información estadística del Instituto

Colombiano de Crédito Educativo y Estudios Técnicos en el Exterior (2016)

Sin embargo, aun cuando la mayor participación de los beneficiarios pertenece a los tres primeros estratos, (ver figura 18) se observa la existencia de población beneficiaria correspondiente a los estratos 4, 5 y 6 , sumando para la primera versión 61 beneficiarios y para la segunda un total de 80 . Es decir, aunque la política del gobierno a través de la implementación de este tipo de programas se direcciona al beneficio de población en condición socioeconómica desfavorable, se presenta una ausencia en materia de seguimiento para evitar que estratos considerados aptos para cubrir una matrícula universitaria se encuentren incluidos dentro del programa, generando exclusión y aún más acaparamiento de oportunidades frente a la población que por sus condiciones heredadas no puede lograr obtener un cupo en una universidad pública o financiar una matrícula privada. De tal manera, con el beneficio otorgado a población proveniente de estratos elevados se deja de cubrir un total de 141 beneficiarios que se encuentran en condiciones más vulnerables.

Sin embargo, a pesar de que el programa ha beneficiado a 141 estudiantes provenientes de estratos socioeconómicos elevados, desorientando el objetivo del mismo, el debate no debería centrar su atención frente al tipo de población beneficiaria, ya que bajo una lógica universalista todos los bachilleres deberían contar con la garantía en el acceso a la educación superior. No obstante, la política de focalización implementada bajo este tipo de crédito educativo pone en tela de juicio el derecho que presentan los ciudadanos frente al acceso a la educación.

\section{Género}

Dentro del total de población beneficiaria para la primera versión, la cual correspondió a 10.141 , se identifica una mayor proporción de hombres, de 5791 beneficiarios, en comparación con 4350 mujeres; siguiendo la tendencia para la segunda versión con un total de 12.710 beneficiarios, distribuidos en 7374 hombres y 5336 mujeres. Existe una participación más alta de hombres en ambas versiones de crédito, a pesar de que la población femenina es quien presenta menores tasas de deserción en la educación superior. 

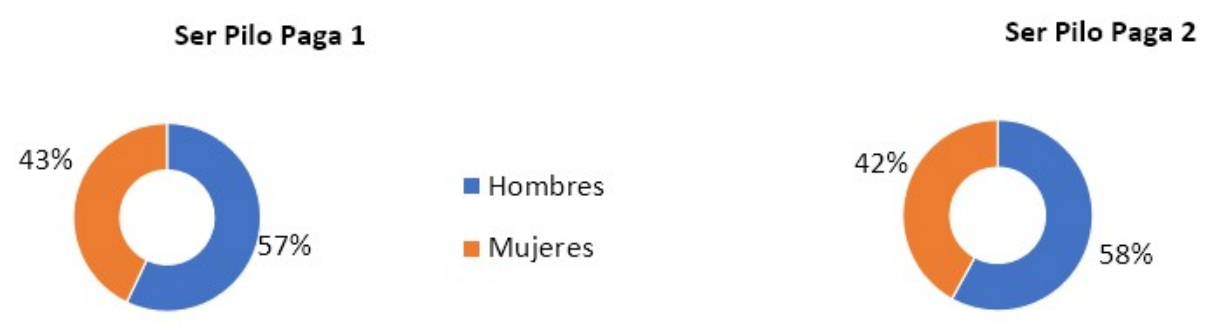

$$
\begin{aligned}
& \text { - Hombres } \\
& \text { - Mujeres }
\end{aligned}
$$

FIGURA 19

Total de beneficiarios Ser Pilo Paga 1 y Ser Pilo Paga 2 por género

elaboración propia a partir de la información estadística del Instituto

Colombiano de Crédito Educativo y Estudios Técnicos en el Exterior (2016)

Adicionalmente, el comportamiento en la selección de los programas arroja una tendencia frente al área de conocimiento, dado que la población masculina opta por programas relacionados con ciencias exactas, mientras que la población femenina propende por aquellas carreras relacionadas con ciencias humanas y de la salud. A pesar de la existencia casi proporcional de hombres y mujeres como beneficiarios del programa (figura 19), se identifica que este no logra eliminar asimetrías de género en materia de educación superior, debido a que prevalece la tendencia en la selección, por parte de población femenina, de programas académicos considerados históricamente femeninos, como es el caso de las ciencias de la salud y las ciencias humanas; comportamiento determinado por construcciones sociales en el que prima el rol asignado a la mujer como ser reproductor de la familia y custodio del hogar; y de la educación básica y media recibida, la cual ha estado orientada al desarrollo de actividades relacionadas con manualidades, que le permiten asumir los roles sociales impuestos en la familia. 

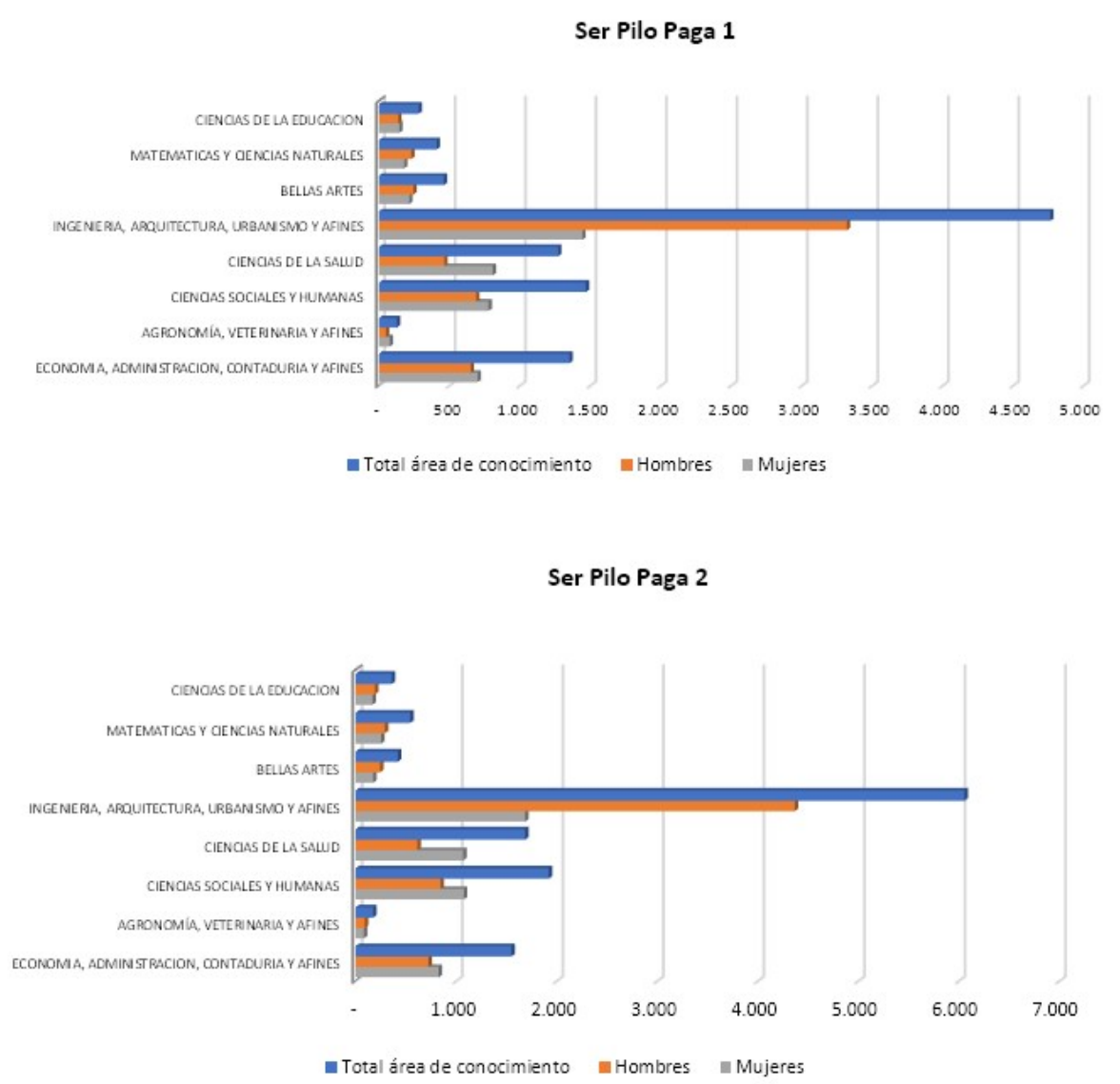

FIGURA 20

Selección de programas académicos por área de conocimiento y sexo elaboración propia a partir de la información estadística del Instituto Colombiano de Crédito Educativo y Estudios Técnicos en el Exterior (2016)

Por su parte, la selección realizada por la población masculina tiende a estar dirigida a programas relacionados con las ingenierías o matemáticas, dado que históricamente se ha concebido que los hombres son quienes mejor se desempeñan en este campo de conocimiento. De la misma manera, la existencia de desigualdades de género en materia educativa se traduce en desigualdades relacionadas con el mercado laboral posterior a la finalización de la educación superior, ya que aun cuando la población femenina presenta el mismo nivel académico que los hombres, perciben una menor remuneración (Quintero, 2016).

En lo referente a población étnica y en condición de discapacidad que accede al programa, no se cuenta con información disponible.

\section{Tú Eliges}

Este programa es una modalidad de crédito educativo, constituida por cinco opciones de financiación, la cual se encuentra dirigida a estudiantes que quieran cursar o se encuentren cursando cualquier tipo de pregrado o posgrado dentro y fuera del país. El valor del crédito tiene diferentes modalidades en las cuales cubre desde el 100\% de la matricula, que puede ser financiado durante o al final de cursar el programa académico en su totalidad. De acuerdo con lo establecido por el Icetex, el periodo de vigencia del crédito empieza a regir a partir de que este sea adjudicado al beneficiario. Este programa de crédito educativo entró en vigor a partir del segundo semestre de 2015 como sustitución del programa de crédito ACCES. De tal manera, la información 
aquí analizada corresponde al periodo comprendido entre el segundo semestre de 2015 y el primer semestre de 2016.

\section{Nivel departamental}

Durante el periodo de análisis fueron otorgados un total de 20.442 créditos de largo plazo a nivel nacional. Del total, el Distrito Capital fue el que mayor cantidad de beneficiarios obtuvo con 4934, seguido de Valle del Cauca con 1768 y Atlántico con 1319. De acuerdo con la figura 21, la participación de los departamentos mencionados frente al total de beneficiarios correspondió a $24.14 \%, 8.65 \%$ y $6.45 \%$, respectivamente.

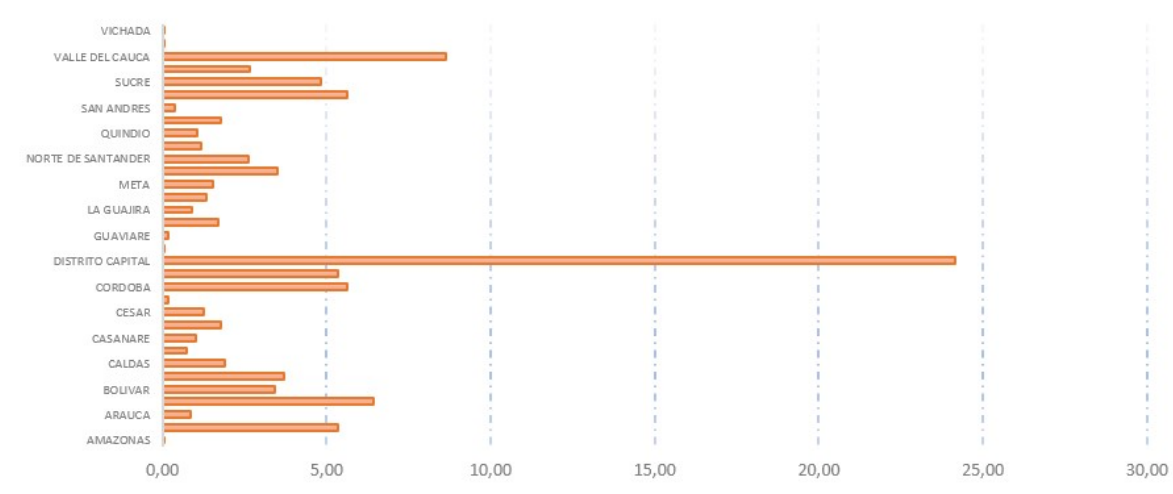

FIGURA 21

Porcentaje de beneficiarios de crédito educativo por departamento elaboración propia a partir de la información estadística del Instituto Colombiano de Crédito Educativo y Estudios Técnicos en el Exterior (2016)

El comportamiento de los departamentos señalados, frente al predominio en la cantidad de beneficiarios, es un reflejo de la situación económica que enfrentan, dado que departamentos como Atlántico, Valle del Cauca y el Distrito Capital se caracterizan igualmente por presentar baja proporción de personas con necesidades básicas insatisfechas (NBI). De acuerdo con el DANE (Departamento Administrativo Nacional de Estadística, 2016a), la proporción de personas con NBI para Bogotá asciende a 9.20\%, para el Valle del Cauca se ubica en $15.68 \%$ y para Atlántico en $24.74 \%$, lo cual permite que mayor número de personas pueda demandar créditos educativos. En contraposición a esta situación, departamentos con el menor porcentaje de participación de beneficiarios se caracterizan por contar con índices de NBI elevados, entre ellos se encuentra Chocó con una proporción de personas bajo NBI de 79.19\%, seguido de Guainía con 60.62\% y Amazonas con $44.41 \%$, lo cual refleja las pocas posibilidades que presenta la población para acceder a un crédito educativo dada la incapacidad de endeudamiento.

\section{Tipo de formación}

Dentro del tipo de formación financiado a través del crédito se encuentra la de tipo universitario, la formación técnica profesional y la tecnológica. Durante el periodo de análisis, se observa que la universitaria es la que presenta una mayor cantidad de beneficiarios, con un total de 19.303, mientras que la formación técnica profesional es la que presenta la menor cantidad de beneficiarios con 167 

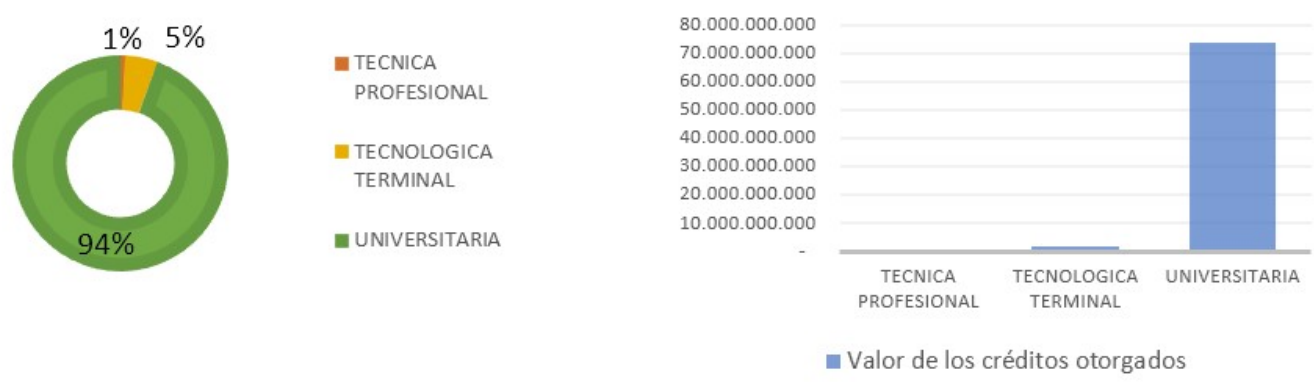

FIGURA 22

Distribución de beneficiarios y valor de créditos otorgados por tipo de formación elaboración propia a partir de la información estadística del Instituto Colombiano de Crédito Educativo y Estudios Técnicos en el Exterior (2016)

Al presentar la formación universitaria, se identifica que el valor de los créditos es igualmente elevado para este tipo de formación, ya que el costo asociado es mucho más alto. El valor de los créditos otorgados para este tipo de formación ascendió a \$73.553.758.838, mientras que para la formación técnica se ubicó en \$299.826.214 (figura 22). La mayor participación de la formación universitaria da cuenta de la prioridad jerárquica brindada, ya que las personas beneficiarias optan por acceder a esta, al considerar que su retribución futura en materia salarial será mucho más significativa en comparación con la formación técnica y tecnológica.

De tal manera, la población que no cuenta con capacidad de endeudamiento para el acceso a un crédito opta por acceder directamente al mercado laboral o por la formación técnica y tecnológica ya que representa una opción económica, de duración corta y que se acopla a sus necesidades, puesto que este tipo de población en muchos casos trabaja y requiere estudiar al mismo tiempo. Al brindar mayor prelación a la formación universitaria se consolida una relación jerárquica en materia de superioridad e inferioridad frente al tipo de formación, ya que la población universitaria tendrá mejores oportunidades laborales y económicas frente a la población que accede a la formación técnica y tecnológica. De acuerdo con el Observatorio Laboral para la Educación (2016), en la medida en que se obtengan mayores niveles de formación educativa, las oportunidades para el acceso al mercado laboral aumentan, así como los niveles salariales.

\section{Estrato socioeconómico}

A nivel de estrato socioeconómico predominan los beneficiarios provenientes de estratos 1,2 y 3 , quienes en su mayoría presentan pocas posibilidades de acceso a la educación superior pública, por lo cual tienden a optar por demandar créditos educativos. Del total de población beneficiaria, se evidencia que aquella perteneciente al estrato 2 es la que presenta una mayor proporción dentro del total, con un $42 \%$, seguida del estrato 1 con un $28 \%$, tal como lo indica la figura 23 . 

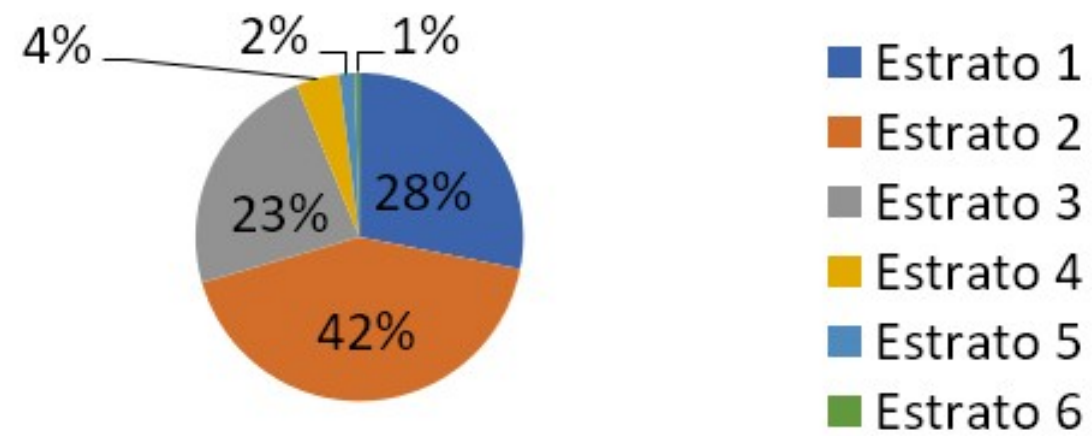

FIGURA 23

Distribución de beneficiarios por estrato socioeconómico elaboración propia a partir de la información estadística del Instituto Colombiano de Crédito Educativo y Estudios Técnicos en el Exterior (2016)

El contar con un sistema de educación superior insuficiente para el acceso de toda la población procedente de la educación secundaria, conduce a que se opte por la financiación de la educación a través de créditos educativos, es decir, la población se ve forzada a demostrar una capacidad de endeudamiento, individual o familiar, suficiente para lograr acceder al sistema. No obstante, los beneficiarios de los créditos perciben esta opción como positiva, aun cuando la deuda adquirida representa una gran responsabilidad futura.

A su vez, la dificultad presentada por los estudiantes de los tres primeros estratos para acceder a las instituciones de educación superior públicas, dada la calidad de la educación previa recibida, las dificultades en la obtención de puntajes elevados en las pruebas Saber 11, y los resultados en las pruebas de acceso en algunas instituciones públicas conllevan a la financiación de la educación superior privada, determinando la entrada de aquella única población que cuenta con capacidad de pago.

No obstante, la financiación de la educación superior a través de créditos educativos se concentra en población de condición socioeconómica vulnerable, la cual tiene que endeudarse para acceder al sistema y adicionalmente demostrar ser "pila" de acuerdo con los puntajes de Estado exigidos. El contar con un crédito educativo condiciona el ingreso obtenido por los beneficiarios durante el curso de su carrera o al momento de finalizarla

\section{Género}

A diferencia de la tendencia presentada en el programa Ser Pilo Paga, en sus dos primeras versiones, en el programa de crédito Tú Eliges se identifica una mayor participación de población femenina frente a la demanda de créditos, con un total de beneficiarias que asciende a 11.953, en comparación con la población masculina que representó 8489 beneficiarios. 


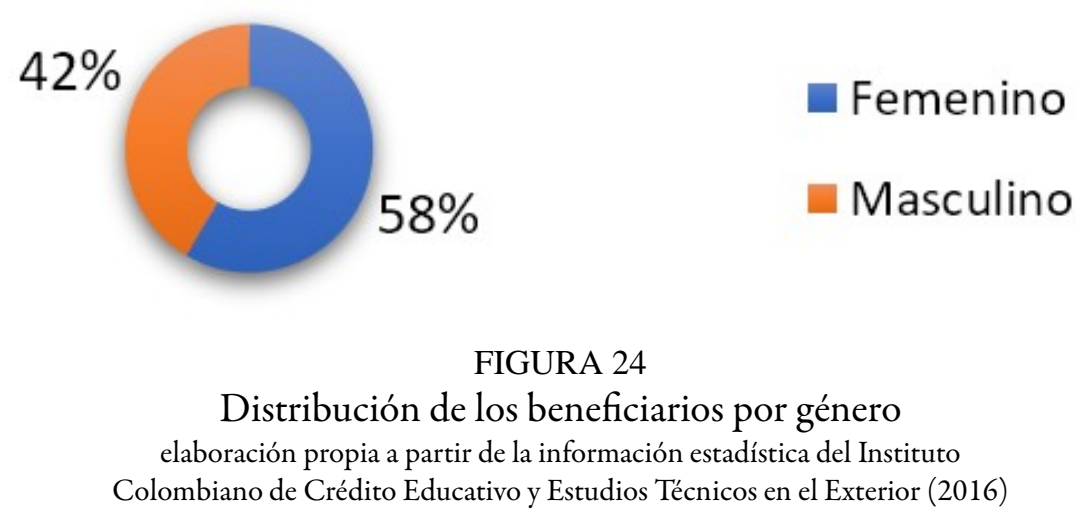

Esta conducta se ve aún más reforzada por el comportamiento presentado frente a la deserción en la educación superior, ya que la población femenina presenta una menor tasa de deserción (46\%) en comparación con la reportada por la población masculina (54\%) (Sistema para la Prevención de la Deserción de la Educación Superior, 2016).

\section{Tipo de población}

Dada la diversidad cultural de la población colombiana, es necesario conocer si programas como Tú Eliges toman en cuenta población afrocolombiana, raizal e indígena, y que permitan igualmente su participación en el sistema educativo. De tal manera, de acuerdo con el Icetex, se evidencia una participación de este tipo de población del 5\%, con un total 1035 beneficiarios para los tres grupos, siendo 789 los beneficiarios afrocolombianos, 200 beneficiarios pertenecientes a la comunidad indígena y 46 a la población raizal. ${ }^{5}$

\section{-AFROCOLOMBIANO - INDÍGENA - RAIZAL}
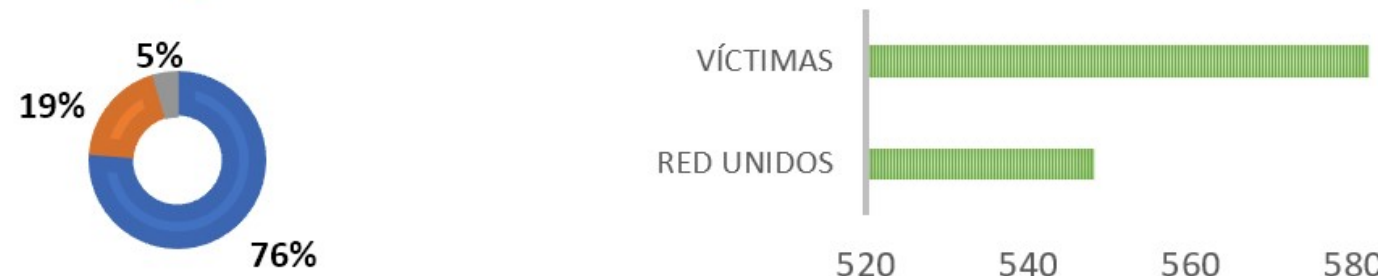

600

FIGURA 25

Porcentaje de beneficiarios por tipo de población

elaboración propia a partir de la información estadística del Instituto

Colombiano de Crédito Educativo y Estudios Técnicos en el Exterior (2016)

Por otra parte, al analizar el porcentaje de participación que presentan los diferentes grupos étnicos dentro del total de población en edad entre 15 a 24 años $^{6}$, se identificó que la población afrocolombiana representa el $11 \%$ dentro del total en dicha edad, seguido de la población indígena con el 3.4\%, y la población raizal con el $0.1 \%$. 


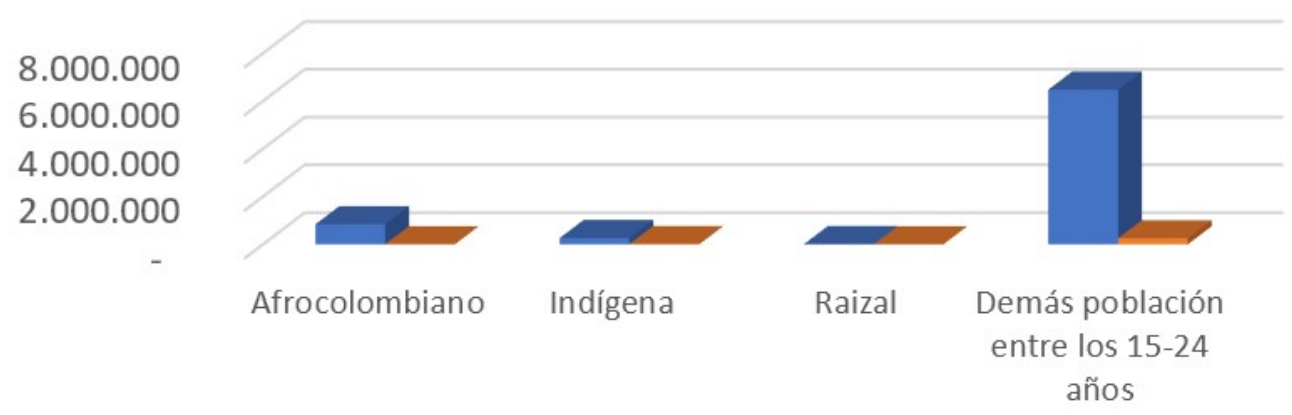

\author{
Población de 15 -24 años Total beneficiarios \\ FIGURA 26 \\ Población entre los 15 y 24 años de edad y total de beneficiarios, por grupo étnico \\ elaboración propia a partir de datos suministrados por derecho de \\ petición (Departamento Administrativo Nacional de Estadística, 2016b)
}

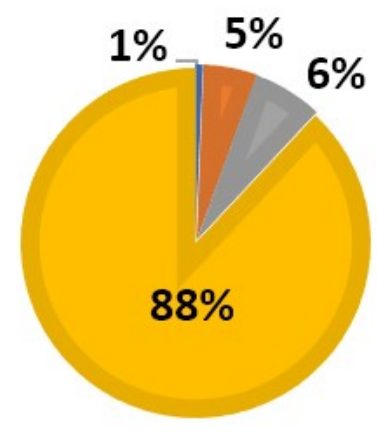

Afrocolombiano

Indígena

- Raizal

- Demás población entre los 1524 años

FIGURA 27

Participación de beneficiarios sobre el total de población, por grupo étnico entre los 15 y 24 años de edad elaboración propia a partir de datos suministrados por derecho de petición (Departamento Administrativo Nacional de Estadística, 2016b)

Sin embargo, al considerar los grupos étnicos entre el rango de 15 a 24 años de edad, grupo demandante de educación superior, y el total de beneficiarios para los programas ACCES y Tú Eliges, en el periodo comprendido entre 2009 hasta el primer semestre de 2016, se logra observar (figura 28) que los dos programas cubrieron el $1 \%$ del total de población afrocolombiana, para la población indígena se abarcó el $5 \%$ dentro del rango de edad establecido, y finalmente para la población raizal este porcentaje se ubicó en el 6\%.

De tal manera, aunque los dos programas tengan en consideración los grupos étnicos, se logra observar que la participación de estos dentro del total de población en edad demandante de educación superior es considerablemente baja, lo cual puede indicar que los programas no tienen como objetivo fundamental el direccionar estos créditos a los diferentes grupos étnicos que históricamente se han visto en desventaja en materia de acceso y permanencia en el sistema educativo (Mora, 2016a). De la misma manera, al considerar el mérito como determinante del acceso, incluso para esta población, se conduce a una reproducción del mecanismo de desigualdad denominado distanciamiento y a su vez a un deterioro de la situación de igualdad en la educación superior, dado que a través del logro individual se dejan de lado los determinantes previos e históricos que dificultan que dicha población tenga el mismo nivel de acceso a la educación superior.

De acuerdo con el estudio realizado por Cárdenas (citado en Mora, 2016a), aquellos departamentos con mayor cantidad de población indígena y afrocolombiana presentan menor desempeño en las Pruebas Saber, y específicamente los grupos étnicos que han sufrido algún tipo de violencia. Asimismo, la poca participación de la población indígena y afrocolombiana en la educación superior se encuentra fuertemente relacionada con la desventaja presentada en la cobertura educativa en los primeros años de edad de este tipo de población, 
lo que indica que la relación de niños afrocolombianos que asisten a un centro educativo en edad temprana asciende a 4 de cada 10 en comparación con la población indígena cuya relación se ubica en 2 de cada 10 .

De la misma manera, el programa toma en consideración población perteneciente a la Red Unidos, que se constituye como una estrategia del orden nacional que busca beneficiar a las familias que se encuentran bajo condición de pobreza y pobreza extrema, mediante el mejoramiento de sus condiciones de vida (Departamento Nacional de Planeación, 2016). De tal manera, el programa de crédito otorgó para el periodo de análisis un total de 548 créditos, que representa el 2.6\% dentro del total de créditos otorgados a nivel nacional. Asimismo, fueron conferidos créditos educativos a población víctima de la violencia, los cuales ascendieron a 582 , representando el $2.8 \%$ dentro del total.

TABLA 2

Total de beneficiarios en condición de discapacidad y valor del crédito otorgado elaboración propia a partir de la información estadística del Instituto Colombiano de Crédito Educativo y Estudios Técnicos en el Exterior (2016)

\begin{tabular}{lrr}
\hline & $\mathbf{N}^{\circ}{ }^{\circ}$ beneficiarios & Valor del crédito \\
\hline $\begin{array}{l}\text { En condición de } \\
\text { discapacidad }\end{array}$ & 48 & 148.785 .269 \\
\hline Total general & 20.442 & 75.554 .172 .244 \\
\hline
\end{tabular}

Por otra parte, de acuerdo con el Icetex (2016), fueron otorgados créditos educativos para la población en condición de discapacidad, los cuales se ubicaron en 48 beneficiarios, representando el $0.23 \%$ del total. A partir del censo de población y vivienda 2005, el DANE establece la existencia de 857.132 personas en condición de discapacidad, de las cuales aquellas en el rango de edad entre 17 y 21 años, donde se incluye a la población demandante de educación superior, se encuentran 80.656 personas; es decir que del total de población demandante de educación superior, tan solo es atendido por este tipo de programa el $0.06 \%{ }^{7}$ Adicionalmente, la población en condición de discapacidad es una de las que presenta una elevada desigualdad en materia educativa, dado que de acuerdo con la Corte Constitucional,

el 6.3\% de la población colombiana presenta limitaciones permanentes, y que de este porcentaje el 33.3\% no tiene nivel educativo y el $29.1 \%$ tiene nivel de básica primaria incompleta. Para el caso de la educación superior, cerca del $2.34 \%$ tiene algún nivel en educación de este nivel, ya sea técnica, tecnológica o profesional, el 1\% han culminado sus estudios superiores y el $0.1 \%$ han cursado postgrados. (Corte Constitucional de Colombia, 2011, p. 16)

Adicionalmente, para analizar la vinculación inmediata de los bachilleres a la educación superior, el Ministerio de Educación Nacional (MEN) ha desarrollado un instrumento denominado "Tasa de absorción a la educación superior" (figura 28), el cual tiene por objetivo cuantificar el porcentaje de personas graduadas de la educación media que logran ingresar a un programa de educación superior. Para el periodo 2013-2014, es decir los estudiantes graduados en el periodo 2013 y que ingresaron a la educación superior en el año 2014, la tasa de absorción correspondió al 37.3\%, siendo Bogotá D. C., Santander y Cundinamarca, los departamentos que mayor tasa da absorción presentaron, ubicándose en el 51.6\%, 45.2\% y 44\%, respectivamente. Asimismo, para el periodo 2014-2015, la tasa de absorción se ubicó en el $37.4 \%$ a nivel nacional, siendo San Andrés y providencia el de mayor tasa de absorción dentro del total de departamentos, con un valor de $55.5 \%$, seguido se encuentra Guaviare con 51.7\% y Bogotá D. C. con 50.3\%. 

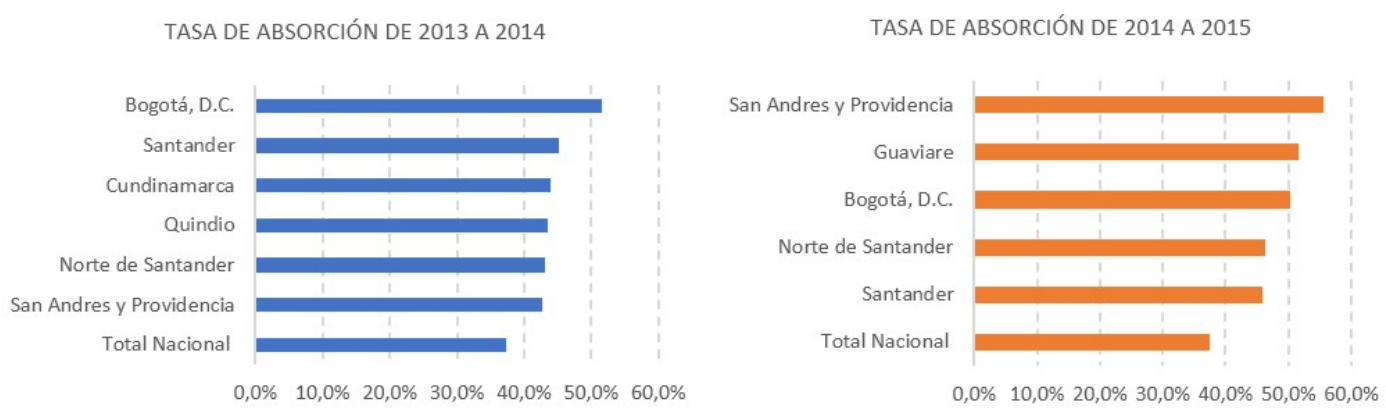

FIGURA 28

Tasa de absorción de la educación superior por departamento, periodos 2013-2014, 2014-2015 Ministerio de Educación Nacional (2016a)

De acuerdo con la información suministrada por el MEN, el número de bachilleres provenientes de grado once para el periodo 2014 y 2015 ascendió a 476.130 y 469.198, respectivamente. Por su parte, para el mismo periodo, el programa Ser Pilo Paga contó con un total de beneficiarios de 10.141, a lo cual se puede indicar que el programa cubrió el $2.1 \%$ del total de bachilleres. De la misma manera, el programa ACCES contó con un total de 42.442 beneficiarios, donde cubrió el $8.9 \%$ de bachilleres. Por su parte, para el año 2015, el porcentaje de beneficiarios que acaparó el programa Ser Pilo Paga ascendió al 2.7\%, con un total de 12.710 beneficiarios. Al tomar en consideración que el programa ACCES tuvo vigencia hasta el primer semestre de 2015 , se identifica una participación del $5 \%$, con un total de 23.511 créditos otorgados.

De tal manera, puede observarse que ambos programas lograron cubrir aproximadamente el $11 \%$ de la población bachiller en el periodo 2014, es decir, un total de 52.583 bachilleres. Igualmente, para el 2015 se cubrió el 7.7\% de bachilleres, representando un total de 36.221. Así, para ambos programas, se puede analizar que fueron cubiertos un total de 88.804 bachilleres, y quedaron sin cubrir bajo estas modalidades de crédito 856.524; los cuales estarán condenados a quedar por fuera del sistema o a acceder a educación de baja calidad, como una opción para jóvenes considerados pobres (Gómez, 2015).

\section{Conclusiones}

Frente al surgimiento de desigualdades en materia de acceso y permanencia, el Gobierno Nacional ha optado por la consolidación de los créditos educativos y el subsidio a la demanda como mecanismos garantes del acceso a la educación superior, basados en una lógica de focalización del gasto público. En este contexto, a partir del año 2002 se instauran en el país los programas de crédito educativo y subsidio a la demanda Acceso con Calidad a la Educación Superior (ACCES), el programa Tú Eliges y Ser Pilo Paga.

Aunque estos programas presentan una intencionalidad en corregir problemas distributivos y de inclusión por género, a través de una política preferencial hacia la población económicamente más vulnerable y, en algunos casos, hacia las mujeres, se identifica que en los mismos prevalece una lógica individualista basada en una igualdad de oportunidades, tal como la menciona Dubet (2011), en la cual el mérito o esfuerzo individual se convierte en el garante para acceder a la educación superior, materializada en el rendimiento académico demostrado por los estudiantes en los puntajes obtenidos en las pruebas de Estado, es decir, los más favorecidos dentro de los desfavorecidos son los que logran acceder al sistema de educación superior.

Bajo la lógica de igualdad de oportunidades se observa la dificultad que presentan los programas para mejorar la igualdad en el sistema de educación superior en Colombia, dado que no intentan corregir o eliminar los mecanismos reproductores de desigualdad establecidos por Tilly (2000) y Therborn (2015) como son el acaparamiento de oportunidades, el distanciamiento y la jerarquización, los cuales reproducen las brechas sociales existentes en el sistema de educación superior en Colombia. 
La importancia brindada al mérito individual y la competencia dentro de una lógica de igualdad de oportunidades ha conducido a que el mecanismo de desigualdad denominado acaparamiento de oportunidades, establecido por Tilly (2000), no logre ser eliminado o reducido, dado que un grupo no favorecido de la sociedad logra acaparar las pocas oportunidades presentes en el sistema de educación superior; dejando por fuera a los no tan "pilos", y cuyo esfuerzo no fue suficiente para lograr un cupo; dando a entender que el fracaso en el ingreso al sistema se atribuye a su falta de responsabilidad o talento.

La concepción del mérito presente en los tres programas no logra evidenciar los aspectos relacionados con la calidad de la educación media y básica recibida, la cual puede ser un determinante de los puntajes de Estado obtenidos. De tal manera, el acaparamiento de oportunidades es evidenciado nuevamente en el otorgamiento de los créditos a nivel regional, debido a que aquellos departamentos que cuentan con mejores condiciones socioeconómicas, y con una tendencia menor frente al porcentaje de población ubicada por fuera del sistema, son los que presentan una mayor cantidad de estudiantes beneficiarios, en comparación con departamentos cuyas necesidades básicas insatisfechas son considerablemente elevadas.

De tal manera, los potenciales beneficiarios de los programas, y quienes logran acaparar las pocas oportunidades ofrecidas, corresponden a aquellos que presentan una ventaja relativa frente a los peor situados a nivel nacional, reduciendo las posibilidades de tener una oportunidad de acceso al sistema de educación superior para estos últimos. La existencia de este mecanismo en el sistema de educación superior, y su reproducción a través de la ejecución de estos programas, conduce a que las brechas sociales existentes se profundicen aún más, dado que al acaparar mayores oportunidades a nivel educativo se traducirá en mayor acaparamiento de oportunidades a nivel laboral y salarial posteriormente, enfatizando la desventaja que presentan unos estudiantes con respecto a otros, ya que los que no lograron acceder al beneficio del crédito público tienen que tomar la decisión de adquirir un crédito privado, acceder únicamente a la formación técnica y tecnológica o simplemente salir del sistema.

Por otra parte, al basar la ejecución de los programas en el mérito y la competencia se gesta un escenario o proceso de adaptación (Tilly, 2000), dado que al incrementar sustancialmente el puntaje de las pruebas de Estado como criterio de selección y de mejoramiento en el desempeño de los estudiantes, hace que estos se adapten a los condicionamientos establecidos por el programa y propendan por una mejor preparación con el objetivo de obtener mejores puntajes y lograr un cupo en este tipo de programa.

Adicionalmente, los tres programas de crédito analizados no logran reducir el mecanismo de jerarquización desarrollado por Therborn (2015), dado que en diferentes aspectos lo refuerzan y mantienen dentro de sistema de educación superior que adopta una forma piramidal. Por una parte, los programas enfatizan la importancia otorgada a las instituciones de educación superior acreditadas bajo estándar de alta calidad, dejando de lado a las públicas, e incluso privadas que no cuentan con dicha certificación.

Los tres programas de crédito brindan prelación a las instituciones que cuenten con este reconocimiento, sin propender por el mejoramiento de aquellas que presentan menores niveles de calidad. En la medida en que los programas solo se enfoquen en aquellas instituciones de educación superior acreditadas de alta calidad, se mantendrá una estructura jerárquica y piramidal, en la cual aquellos que no fueron beneficiarios tendrán que ingresar a las instituciones que no cuentan con dicha certificación.

Igualmente se observó que las instituciones de educación superior acreditadas como de alta calidad, tanto públicas como privadas, se encuentran ubicadas en su mayoría en ciudades principales como Bogotá, Medellín, Barranquilla, entre otros; lo cual manifiesta la centralización de los programas y la falencia de estos en materia de fomento del crecimiento de la matrícula en instituciones de educación superior ubicadas en zonas periféricas, o en el fomento en el mejoramiento de la calidad que permita que un mayor número de instituciones sean certificadas bajo este criterio.

A su vez, el mecanismo de jerarquización se encuentra presente en la distribución de los beneficiarios por tipo de formación, dado que existe una elevada participación de la formación universitaria cercada al 90\%, en comparación con la formación técnica y tecnológica, cuya participación está enfocada a población pobre 
y con bajos puntajes en pruebas de Estado, quienes tienen que acceder a este tipo de formación por factores económicos y de educación previa, que no les permite el pago de una matrícula universitaria ni el logro de los puntajes exigidos en instituciones públicas. Aproximadamente el 20\% de los estudiantes que logran ingresar a la formación técnica y tecnológica provienen de familias cuyos ingresos no superan los dos salarios mínimos mensuales legales vigentes (Mora, 2016a).

De tal manera, se puede decir que estos programas no logran reducir las brechas existentes en materia de la estructura piramidal de la educación superior en el país; debido a que la formación universitaria sigue identificándose como aquella de mayor progreso social.

Por su parte, el mecanismo que determina una distancia entre individuos dadas unas condiciones sociales, culturales y económicas, y que es denominado por Therborn (2015) como distanciamiento, es evidenciado en relación con las condiciones previas de las personas en relación con su origen regional, pertenencia étnica y discapacidad. Para el caso del origen regional, las regiones que presentan condiciones de NBI elevadas son las que menor cantidad de beneficiarios perciben dentro del total, y son las que, a su vez, han presentado en los últimos años un elevado porcentaje de población por fuera del sistema. Por consiguiente, las condiciones socioeconómicas de los estudiantes determinan la posibilidad para el acceso al sistema de educación superior, es decir, los estudiantes que cuentan con mejores condiciones socioeconómicas y culturales presentan un mejor rendimiento académico traducido en las pruebas de estado, lo cual posibilita su acceso al sistema de educación superior, en comparación con población que cuenta con elevadas carencias en materia económica y cultural.

$\mathrm{Al}$ tomar en consideración las NBI de los diferentes departamentos y el porcentaje de población que logra acceder al sistema educativo a través de la obtención de créditos, puede observarse la existencia de este mecanismo de reproducción de desigualdad, el cual manifiesta la distancia presente entre dos individuos dadas unas condiciones iniciales previas

Por otra parte, en lo referente a población en condición de discapacidad, se observó igualmente que continúa presentando niveles de desigualdad, dado que las condiciones de distanciamiento que las caracteriza, por sus condiciones de salud, no son abarcadas a profundidad por los programas, ya que estos logran acaparar el $0.2 \%$ de este tipo de población. Este mismo mecanismo se observa para los grupos étnicos, quienes enfrentan condiciones desfavorables en el acceso y permanencia al sistema de educación superior; aún con la ejecución de estos programas solo se logra beneficiar al $1 \%$ de la población afrocolombiana, al $5 \%$ de la población indígena y al $6 \%$ de población raizal.

Finalmente, a pesar de contar con la información estadística suministrada por el El Instituto Colombiano de Crédito Educativo y Estudios Técnicos en el Exterior (Icetex) y el Ministerio de Educación Nacional (MEN), existen falencias en materia de datos, entre los que se encuentran la ausencia de información de proyecciones de población por grupos étnicos, puesto que solo existe, para el año 2005, información relacionada con la edad demandante de educación superior para grupos étnicos, estadísticas relacionadas con las carreras demandadas por los beneficiarios, y la participación que presentan los tipos de formación por departamento; lo cual limita el análisis. Por otra parte, a pesar de identificar aspectos positivos y negativos con la implementación de los programas de crédito, surgen preguntas fuera de este alcance, pero que servirían de base para futuras investigaciones, como son: ¿por qué existe mayor proporción de mujeres en los créditos ACCES y Tú Eliges?, ¿la población femenina presenta menor temor frente a la población masculina para adquirir un crédito educativo?, ¿cuál es la condición actual de los beneficiarios de los programas de crédito educativo?, ¿ presentan mejores o peores condiciones posterior al programa?

\section{Referencias}

Corte Constitucional. (2011). Sentencia T-551. 
Consejo Nacional de Educación Superior. (2014). Acuerdo por lo superior 2034. Propuesta de política pública para la excelencia de la educación superior en Colombia en el escenario de la paz. http://www.mineducacion.gov.co/1 621/articles-344500_Brochure_acuerdo_Superior.pdf

Departamento Administrativo Nacional de Estadística. (2016a). Necesidades Básicas Insatisfechas(NBI). http://www.dane.gov.co/index.php/estadisticas-por-tema/pobreza-y-condiciones-de-vida /necesidades-basicas-insatisfechas-nbi

Departamento Administrativo Nacional de Estadística. (2016b). Proyecciones de población. http://www.dane.gov.co/i ndex.php/estadisticas-por-tema/demografia-y-poblacion/proyecciones-de-poblacion

Dubet, F. (2011). Repensar la justicia social, contra el mito de la igualdad de oportunidades. Siglo XXI Editores.

García, M., Espinosa J., Jiménez F., y Parra, J. D. (2013). Separados y desiguales. Educación y clases sociales en Colombia. Ediciones Antropos.

Giraldo, C. (2007). ¿Protección o desprotección social? Ediciones Desde Abajo.

Gómez, V. (2015). La pirámide de la desigualdad en la educación superior en Colombia. Diversificación y tipología de instituciones. Universidad Nacional de Colombia.

Instituto Colombiano de Crédito Educativo y Estudios Técnicos en el Exterior. (2007). Acuerdo No. 035. https://www.icetex.gov.co/dnnpro5/Portals/0/Documentos/La\%20Institucion/Juridica/Junta/2007/A cuerdo\%20035\%20de\%202007.pdf

Instituto Colombiano de Crédito Educativo y Estudios Técnicos en el Exterior. (2016). Tú eliges cómo hacer realidad tus sueños. https://www.icetex.gov.co/dnnpro5/en-us/cr\%C3\%A9ditoeducativo/pregrado.aspx

Ministerio de Educación Nacional. (2016a). Sistema Nacional de Información de la Educación Superior, Indicadores nacionales.http://www.mineducacion.gov.co/sistemasdeinformacion/1735/w3-article-212400.html

Ministerio de Educación Nacional. (2016b). Ser Pilo Paga. http://www.colombiaaprende.edu.co/html/micrositios/1 752/w3-propertyname-3202.html

Montenegro, A., y Meléndez, M. (comps.). (2014). Equidad y movilidad social: diagnósticos y propuestas para la transformación de la sociedad colombiana. Universidad de los Andes; Departamento Nacional de Planeación.

Mora, A. (2015). Veinticinco años de crisis fiscal en Colombia (1990-2014). Acumulación, confianza y legitimidad en el orden neoliberal. Papel Político, 20(1), 63-99. http://doi.org/10.11144/Javeriana.papo20-1.vacf

Mora, A. (2016a). Desigualdades y financiación de la educación básica y media en Colombia: balance y perspectivas. Planeta Paz.

Mora, A. (2016b). La seudorrevolución educativa. Desigualdades, capitalismo y control en la educación superior en Colombia. Pontificia Universidad Javeriana.

Ocampo, J., y Malagón, J. (2012). Los efectos distributivos de la política fiscal en América Latina. Revista Pensamiento Iberoamericano, 10,71-101).

Observatorio de la Universidad Colombiana. (2016). La plata del 'Ser pilo paga' se ha ido a las universidades privadas. http://www.las2orillas.co/la-plata-del-ser-pilo-paga-se-ha-ido-a-las-universidades-privadas/

Observatorio Laboral para la Educación. (2016). Situación laboral de los graduados. http://www.graduadoscolombi a.edu.co/html/1732/w3-article-344801.html

Quintero, O. (2016). La creciente exclusión de las mujeres de la Universidad Nacional de Colombia. Revista Nómadas, 44, 123-145. https://www.doi.org/10.30578/nomadas.n44a7

Sánchez, A., y Otero, A. (2012). Educación y reproducción de la desigualdad en Colombia. Reportes del emisor, 154. http://www.banrep.org/docum/Lectura_finanzas/pdf/re_154.pdf

Sistema para la Prevención de la Deserción de la Educación Superior. (2016). Deserción estudiantil. http://spadies.m ineducacion.gov.co/spadies/JSON.html

Therborn, G. (2015). Los campos de exterminio de la desigualdad. Fondo de Cultura Económica.

Tilly, C. (2000). La desigualdad persistente. Manantial. 


\section{Notas}

* Artículo de investigación científica

[1] Artículo que presenta resultados de investigación desde una perspectiva analítica, interpretativa o crítica del autor, sobre un tema específico, y con el recurso de fuentes originales. Fue desarrollado a partir de la tesis denominada Los programas de crédito educativo y subsidio a la demanda como instrumentos para el mejoramiento de la igualdad en la Educación Superior en Colombia, en el periodo 2002-2016, para optar al grado de magistra en Política Social en la Pontificia Universidad Javeriana.

[2] Para el caso Colombiano los grupos étnicos corresponden a población afrocolombiana, raizal, ROM e indígena.

[3] Esta participación no toma en consideración los sistemas educativos propios de las comunidades indígenas, los cuales son valiosos para su comunidad e identidad, y permiten la continuidad de su diversidad cultural.

[4] De acuerdo con Mora (2015), corresponden a las universidades de: Sucre, Magdalena, Surcolombiana, Francisco de Paula Santander, Amazonía, Pacífico, Guajira, Colegio Mayor de Cundinamarca, Córdoba, Tecnológica de Chocó, Llanos, Pamplona, Cundinamarca, Distrital y Quindío.

[5] En términos de años promedio de educación, es clara también la desventaja sufrida por las poblaciones indígenas y afrodescendientes: tres años de educación para los indígenas, cinco para los afrocolombianos y seis para quienes no reportan pertenencia étnica. Finalmente, de acuerdo con datos del Censo General de 2005, es posible concluir que la asistencia escolar de los jóvenes entre 14 y 17 años es desigual entre los grupos poblacionales, pues alrededor de tres de cada cuatro jóvenes afrocolombianos o sin pertenencia étnica van a la escuela, mientras tan solo uno de cada dos indígenas lo hace. (Cárdenas et al., 2012, citado en Mora, 2015, p. 11)

[6] El rango considerado demandante de educación superior corresponde al de 17 a 21 años, sin embargo, para los grupos étnicos se tomó de los 15 a 24 años por disponibilidad de información, ya que no se cuenta con datos por edades simples. De la misma manera, la población considerada corresponde a la reportada en el censo de población y vivienda del 2005.

[7] Estudios como el desarrollado por Cárdenas (citado en Mora, 2016a) revelan que la población en condición de discapacidad presenta un mayor nivel de desigualdad en materia educativa, ya que el $71 \%$ ha logrado un nivel máximo de educación básica primaria. Asimismo, en lo referente a educación superior, determina que por cada 100 personas que se encuentran en este nivel, 3 presentan una situación de discapacidad.

\section{Licencia Creative Commons CC BY 4.0}

Cómo citar este artículo: Moreno Gamba, A. M. (2020). Los programas de crédito educativo y subsidio a la demanda: instrumentos para el mejoramiento o deterioro de la igualdad en la educación superior en Colombia. Papel Politico, 25. https://www.doi.org/10.11144/Javeriana.papo25.pces. 